\title{
High-Flow Oxygen Administration by Nasal Cannula for Adult and Perinatal Patients
}

\author{
Jeffrey J Ward MEd RRT FAARC
}

\author{
Introduction \\ History \\ Clinical Evaluation of Adult Low-Flow Nasal Cannulas \\ Clinical Evaluation of Low-Flow Perinatal and Pediatric Nasal Cannulas \\ Physical and Anatomical Aspects Affecting Oxygen Delivery and Efficacy \\ of the Nasal Cannula \\ Proposed Benefits of High-Flow Oxygen Via Cannula in Adult and \\ Neonatal Care \\ Equipment for Delivery of High-Flow Nasal Oxygen \\ HFNC for Adults \\ HFNC Equipment for Newborn and Infants \\ Randomized or Quasi-Randomized Trials of HFNC for Adult Patients \\ Observational and Randomized or Quasi-Randomized Trials for Perinatal \\ Patients \\ Observational and Randomized or Quasi-Randomized Trials of HFNC for \\ Pediatric Patients \\ Summary
}

The nasal cannula has been a commonly used patient interface to provide supplemental oxygen since its introduction in the 1940s. Traditionally, it has been categorized as a low-flow device and capable of delivering a $0.4 \mathrm{~F}_{\mathrm{IO}_{2}}$ with flows up to $6 \mathrm{~L} / \mathrm{min}$ to adults with normal minute ventilation. However, there is considerable performance variability among patients and design, which results in an exponential decline in delivered $\mathrm{F}_{\mathrm{IO}_{2}}$ as breathing frequencies increase. The nasal cannula has also been successfully adapted for use in perinatal and pediatric respiratory care; flows are reduced, in the range of $0.25-1 \mathrm{~L} / \mathrm{min}$, due to smaller minute volumes. A decade or so ago, high-flow nasal cannula (HFNC) oxygen therapy was introduced, accompanied by heated humidification systems to prevent the associated drying of upper airway mucosa and to increase patient comfort. Therapeutic flows for adults were in the $15-40 \mathrm{~L} / \mathrm{min}$ range; $\mathrm{F}_{\mathrm{IO}_{2}}$ could be independently adjusted with air/ $\mathrm{O}_{2}$ blending. The $\mathrm{HFNC}$ has also found additional clinical application in perinatal care, as delivery systems with flows $>2 \mathrm{~L} / \mathrm{min}$ could create a distending pressure similar to nasal CPAP. There is a small but growing body of information from clinical trials that supports use of HFNC as an alternative oxygen interface for adults who present with moderate hypoxemia that persists after receiving oxygen by reservoir-bag masks or similar therapy. Clinical observations report greater patient acceptance and comfort versus oxygen masks. HFNC therapy has also been considered valuable in perinatal care in treating the respiratory distress syndrome or supporting patients after extubation similar to nasal CPAP. At present, research-based evidence for the role of HFNC for its perinatal applications remains unclear. This review will identify proposed mechanisms for therapeutic effectiveness, current delivery equipment, guidelines for rational patient application, and direction for further research. Key words: oxygen; nasal cannula. [Respir Care 2013;58(1):98-120. (c) 2013 Daedalus Enterprises] 


\section{High-Flow Oxygen Administration by Nasal Cannula for Adult and Perinatal Patients}

\section{Introduction}

Since the introduction of the nasal cannula in the mid1900s, it has become the most commonly used appliance to provide patients with supplemental oxygen in hospital or ambulatory care. More recently there has been renewed interest and research on its application with gas flows substantially higher than those traditionally recommended. Currently there are no established guidelines and/or decision-making pathways to guide use of the high-flow nasal cannula (HFNC) therapy for adults or infants. A lucid approach to apply specific oxygen delivery devices or systems can be complex. Initially the treatment setting, scenario, presenting signs and symptoms, and patient history are reviewed. Oxygen therapy delivery devices are then considered, based on how their performance characteristics best match their ability to either support or correct the patient's pathophysiologic conditions. Decisions may be modified if other comorbid conditions are found to be present, as well as to deal with issues such as convenience, cost constraints, and patient comfort. The purpose of this review is to summarize physical features, advantages, limitations, and current literature on clinical application of HFNC. The goal will be to assist clinicians in identifying important aspects as to the efficacy of these systems and to guide decisions for their use with adult, perinatal, and pediatric patients.

\section{History}

The clinical application of supplemental oxygen has been credited to Thomas Beddoes and colleagues James Watt and Sir Humphry Davies, who worked in England during the late 1700s. Initial patient interfaces were modified anesthetic masks or mouthpieces; oxygen was manufactured on-site and made available at local apothecaries. By the early 1900s small diameter ( $8-10$ French) rubber catheters were used to stream oxygen directly into the nasopharynx. That technique was clinically applied to victims of World War I gas poisonings, and by the 1920s used in pediatric

Mr Ward is affiliated with the Respiratory Care Program, Mayo College of Medicine, University of Minnesota, Rochester, Minnesota.

Mr Ward presented a version of this paper at the 50th RESPIRATORY CARE Journal Conference, "Oxygen," held April 13-14, 2012, in San Francisco, California.

The author has disclosed no conflicts of interest.

Correspondence: Jeffrey J Ward MEd RRT FAARC, Respiratory Care Program, Mayo College of Medicine, University of Minnesota, 200 1st Street SW, Siebens 10-12D, Rochester MN 55905. E-mail: ward.jeffrey@mayo.edu.

DOI: $10.4187 /$ respcare. 01941 care. ${ }^{1}$ In the United States, Alvan Barach developed a Y-tube to split oxygen flow into a double nasal catheter in order to halve the effect of high flow on nasal mucosa. ${ }^{2}$ By 1925 the British developed a less invasive single and dual oxygen prongs that allowed oxygen to be directed just inside naris or nares. In the mid-1930s, rubber-tipped metal nasal prongs were available. They could be positioned in the nose by using eyeglass frames or held on the forehead by laryngologist head-mirror straps. An early version of the modern plastic over-the-ear nasal cannula appeared by the 1940s, in the form of a blind-ended tube with smaller side tubes to direct flow into the nose. It did not take long for clinicians to recognize cannula limitations in terms of the discomfort and low level of oxygen supplementation to the patient's minute ventilation $\left(\dot{\mathrm{V}}_{\mathrm{E}}\right)$. In response, accessory masks, reservoir bags, or sponge-plugs fitted into the nostril were configured. However, they also recognized that the nasal cannula advantages, compared to masks, was in allowing patients to eat, drink, and speak more easily, and also to avoid the claustrophobic sensation of a face mask. ${ }^{1,3}$

\section{Clinical Evaluation of Adult Low-Flow Nasal Cannulas}

The early clinical literature on oxygen therapy began recommending specific devices based on some objective criteria, especially the ability of equipment to achieve specific ranges of oxygen concentration. That information served clinicians as a general guide in care of patients with varying levels of dyspnea and/or hypoxemia. Selection was also tempered by consideration of comfort or patient acceptance. The first textbook on inhalation therapy suggested that $\approx 30 \%$ oxygen could be obtained with a nasal cannula in adult patients with flow of $4 \mathrm{~L} / \mathrm{min}$. It also advocated (unheated) water-bottle humidification for both nasal cannula and catheter. Barach noted considerable variation in the literature as to the deliverable concentration, depending both on oxygen flow and level of ventilation. ${ }^{4}$ Initial estimation of the oxygen concentration delivery performance was based on crude calculation or speculation.

There has been a considerable research effort to objectively measure the cannula's oxygen performance. A standard technique measured gas samples by aspirating nasopharyngeal samples. Gas analysis was performed by paramagnetic $\mathrm{O}_{2}$ analyzers: the Scholander device or gas chromatographs. ${ }^{3}$ In 1963 Kory et al studied small groups $(10-15)$ of normal subjects. They suggested that in common clinical situations, cannulas could be expected to deliver $\mathrm{F}_{\mathrm{IO}_{2}}$ in the range of $0.35-0.45$ with flows of 8-10 L/ min (Table 1); they also subjectively assessed patient comfort by having subjects rank the cannula with other devices. Subjects found the cannula more comfortable than 


\section{High-Flow Oxygen Administration by Nasal Cannula for Adult and Perinatal Patients}

Table 1. Oxygen Concentrations Delivered by Nasal Cannula

\begin{tabular}{|c|c|c|c|c|}
\hline \multirow[b]{2}{*}{ Flow } & \multicolumn{4}{|c|}{$\mathrm{F}_{\mathrm{IO}_{2}}$, mean (range) } \\
\hline & $4 \mathrm{~L} / \mathrm{min}$ & $6 \mathrm{~L} / \mathrm{min}$ & $8 \mathrm{~L} / \mathrm{min}$ & $10 \mathrm{~L} / \mathrm{min}$ \\
\hline Nasopharyngeal Sampling* & $0.32(0.26-0.39)$ & $0.38(0.34-0.40)$ & $0.35(0.38-0.42)$ & $0.39(0.36-0.45)$ \\
\hline End-Expiratory Samples & $0.26(0.23-0.29)$ & $0.30(0.26-0.37)$ & $0.36(0.30-0.42)$ & $0.45(0.38-0.54)$ \\
\hline
\end{tabular}

face masks, face tents, and catheters, but not as comfortable as an oxygen tent. They also evaluated the effect of closed versus open mouth with flow of $6 \mathrm{~L} / \mathrm{min}$ and found negligible difference with either cannula or catheter. However, these researchers commented that the nasopharyngeal sampling technique was likely influenced by oxygen streaming into the sampling catheter; this would result in higher concentrations. Kory's group estimated that nasopharyngeal samples were approximately 5-10\% higher than what would be expected at the alveolar level. ${ }^{3}$

These data became part of early inhalation therapy textbooks in terms of performance and recommended upper limit of flow for comfort. ${ }^{5}$ With the advent of arterial blood gas (ABG) analysis, a number of studies were published that identified mean $\mathrm{P}_{\mathrm{aO}}$ values and ranges of response variations for normal subjects breathing at various levels of oxygen flow; open and closed mouth breathing was also measured. ${ }^{6}$ A landmark study by Cherniack and Hakimpour measured response to nasal cannulas (over a range of oxygen flows) in patients with a variety of pulmonary diseases and severity of hypoxemia. ${ }^{7}$ Pulmonary function data, including diffusing capacity and the ratio of dead space to tidal volume, allowed the authors to correlate varying levels of oxygen responsiveness to other pathophysiologic indices. Those authors strongly recommended that oxygen administration by cannula should be titrated based on ABGs. They also found that oxygeninduced hypoventilation and worsening hypercarbia were rarely seen in patients with COPD who also presented with elevated baseline $\mathrm{P}_{\mathrm{aCO}}{ }_{2}{ }^{7}$ In 1976 Julian Leigh continuously measured inspired and exhaled oxygen and carbon dioxide levels and breath-by-breath changes with a pneumotachograph. Using an oxygen-carbon dioxide diagram developed by Rahn and Fenn, he extrapolated an intercept on the oxygen axis that represented an average delivered $\mathrm{F}_{\mathrm{IO}_{2}}$. He recorded changes in $\mathrm{F}_{\mathrm{IO}_{2}}$ based on the device being able to match the subject's inspiratory flow, and used that information to distinguish between low-flow variable performance systems. Although Leigh did not specifically measure nasal cannula performance, he touted the ability of large bulk flows through high air flow oxygen entrainment used by the "ventimask," which could better match patient inspiratory flow for more stable oxygen concentrations. ${ }^{8}$
Researchers continued to measure $\mathrm{F}_{\mathrm{IO}_{2}}$ levels produced in the trachea at different nasal cannula flows with more accurate and rapid response devices, such as the mass spectrometer. In 1976 Gibson et al connected a spectrometer to a cricothyroid catheter to measured intra-tracheal $\mathrm{F}_{\mathrm{IO}_{2}}$ at increasing levels of $\dot{\mathrm{V}}_{\mathrm{E}}$ and peak inspiratory flow, to simulate dyspneic breathing patterns. ${ }^{9}$ A similar approach was used by Markovitz and coauthors as they compared direct gas samples from transtracheal catheter and oral catheters with exhaled gas, using the Rahn and Fenn method. ${ }^{10}$ There was good correlation between direct sampling techniques and gas extrapolation; they documented nasal cannula performance $(97 \%$ oxygen concentrator source gas) at 1,3 , and $5 \mathrm{~L} / \mathrm{min}$ while subjects breathed at normal breathing frequency and pattern. In contrast to many undocumented textbook estimates of cannula performance, at low flows they found the delivered $\mathrm{F}_{\mathrm{IO}_{2}}$ increased $0.025(2.5 \%)$ per each $1 \mathrm{~L} / \mathrm{min}$ increase in flow. With nasal cannula flow of $5 \mathrm{~L} / \mathrm{min}$, tracheal sampling recorded $\mathrm{F}_{\mathrm{IO}_{2}}$ of $0.318 \pm 0.005$, and with the exhaled technique $0.327 \pm 0012$ (Fig. 1). ${ }^{10}$

Schacter and colleagues compared hypopharyngeal sampled $\mathrm{F}_{\mathrm{IO}_{2}}$ to those obtained via catheters inserted through "sealed" permanent tracheostomies (Table 2). Mean $\mathrm{F}_{\mathrm{IO}_{2}}$ for hypopharynx or intratracheal samples at $4 \mathrm{~L} / \mathrm{min}$ were $0.27 \pm 1.0$ and $0.26 \pm 1.2$, respectively. They also demonstrated considerable inter-subject variations as well as found substantial secondary air dilution with tachypnea. On $4 \mathrm{~L} / \mathrm{min}$ with a breathing frequency of 40 breaths $/ \mathrm{min}$, mean $\mathrm{F}_{\mathrm{IO}_{2}}$ decreased to $\approx 0.245 .{ }^{11}$ Wettstein and colleagues demonstrated similar effect from tachypnea (doubling of normal breathing frequency) using hypopharyngeal sampling in normal subjects (Fig. 2). ${ }^{12}$

Using Leigh's technique, Bazuaye et al estimated cannula performance and also measured oxygen response with both normal subjects and patients, using an ear oximeter. ${ }^{13}$ That technique found concentrations slightly higher than the cricothyroid catheter data; it also recorded substantial inter-subject variation. At $1 \mathrm{~L} / \mathrm{min}$, normal subjects had a mean $\mathrm{F}_{\mathrm{IO}_{2}}$ of 0.267 , with a coefficient of variation of $10 \%$. With $2 \mathrm{~L} / \mathrm{min}$, mean $\mathrm{F}_{\mathrm{IO}_{2}}$ was 0.301 and the coefficient of variation was $8.6 \%$. Of interest was a much wider variation in patients. At $2 \mathrm{~L} / \mathrm{min}, \mathrm{F}_{\mathrm{IO}_{2}}$ varied from $0.237-0.349$. That group also stated that "the variability with nasal can- 


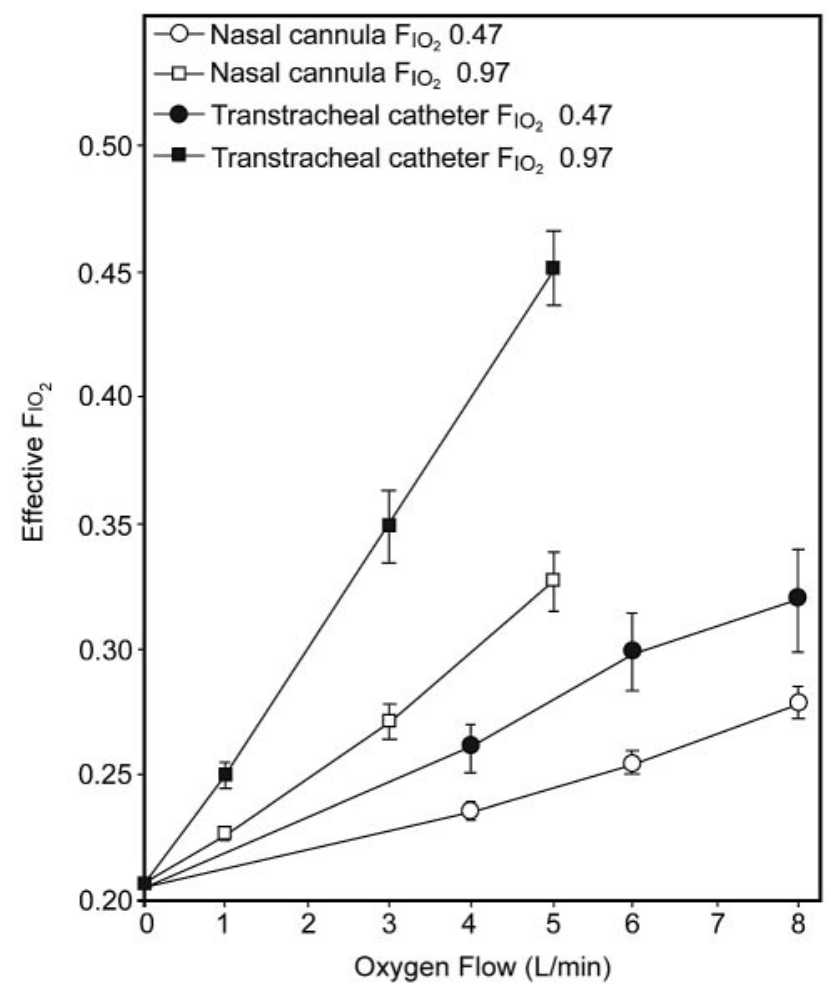

Fig. 1. $\mathrm{F}_{\mathrm{IO}_{2}}$ delivered by nasal cannula measured at mouthpiece, using exhaled gas technique. The $97 \%$ oxygen reflects delivery from an oxygen concentrator. (From Reference 10.)

Table 2. $\quad \mathrm{F}_{\mathrm{IO}_{2}}$ Measured Via Hypopharyngeal and Intratracheal Sampling

\begin{tabular}{lcc}
\hline \hline $\begin{array}{c}\text { Flow From } \\
\text { Cannula } \\
(\mathrm{L} / \mathrm{min})\end{array}$ & $\begin{array}{c}\mathrm{F}_{\mathrm{IO}_{2}} \text { in } \\
\text { Hypopharynx } \\
\text { (mean } \pm \mathrm{SD})\end{array}$ & $\begin{array}{c}\mathrm{F}_{\mathrm{IO}_{2}} \\
\text { in Trachea } \\
\text { (mean } \pm \mathrm{SD} \text { ) }\end{array}$ \\
\hline 1 & $0.22 \pm 0.0$ & $0.23 \pm 0.006$ \\
2 & $0.24 \pm 0.01$ & $0.24 \pm 0.006$ \\
3 & $0.24 \pm 0.01$ & $0.25 \pm 0.01$ \\
4 & $0.27 \pm 0.01$ & $0.26 \pm 0.012$
\end{tabular}

$\overline{\text { (Data from Reference } 11 .)}$

nulas during an exacerbation is likely to be appreciably greater than that found here." 13

The aforementioned research makes clear several points: measurement of nasal cannula $\mathrm{F}_{\mathrm{IO}_{2}}$ is not clinically practical; there is performance variability even among normal subjects; textbook predictions are overly optimistic and not based on research data; and delivered $\mathrm{F}_{\mathrm{IO}_{2}}$ decreases considerably during conditions associated with dyspnea. Because of these 4 factors, the noninvasive pulse oximeter has gained nearly universal acceptance to allow titration of oxygen flow to the cannula. Periodic arterial blood gas analysis would be indicated to also assess hypercapnia and co-oximetric hemoglobin saturation. ${ }^{14-16}$

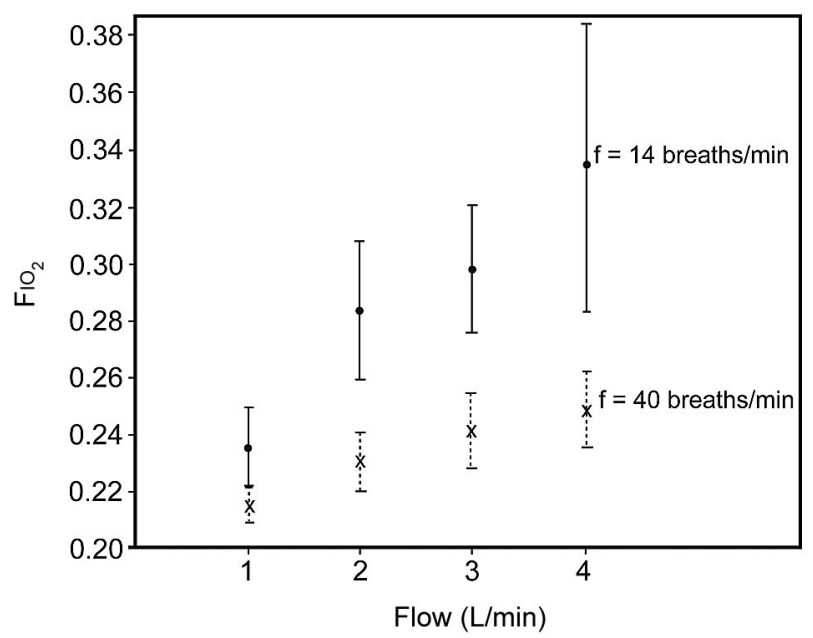

Fig. 2. Mean $\pm \mathrm{SD} \mathrm{F}_{\mathrm{IO}_{2}}$ for pharyngeal sampling of nasal cannula breathing with a breathing frequency (f) 2 times normal for adults. (From Reference 12.)

\section{Clinical Evaluation of Low-Flow Perinatal and Pediatric Nasal Cannulas}

Early approaches to provide enriched oxygen to infants was done using an incubator with supplemental oxygen delivery capability (eg, Isolette) and oxygen tents/hoods. Unregulated levels led to complications of retinopathy of prematurity and wide $\mathrm{F}_{\mathrm{IO}_{2}}$ variations when enclosures were opened for access to infants. ${ }^{17,18}$ The nasal catheter and cannula did become established as standard appliances. Technical issues included use of special low-flow flow meters to accurately measure flows $<3 \mathrm{~L} / \mathrm{min}$. Beginning in the late 1970s, interest in low-flow nasal cannula (LFNC) administration increased for application to newborns with resolving respiratory distress syndrome (RDS) and bronchopulmonary dysplasia. ${ }^{19,20}$

In 1989 Vain and colleagues reviewed 10 neonates with gestational ages ranging from 25-39 weeks, and documented the potential for infants to receive $\mathrm{F}_{\mathrm{IO}_{2}}>0.4$ when flow exceeded $0.5-0.75 \mathrm{~L} / \mathrm{min}^{21}$ Of additional interest was early promotion of flow meters driven by oxygen-air blenders to provide less than $100 \% \mathrm{O}_{2}\left(\mathrm{~F}_{\mathrm{IO}_{2}}\right.$ of $0.4,0.6$, and 0.8 ) to the cannula. They found that independent adjustment of flow and $\mathrm{F}_{\mathrm{IO}_{2}}$ allowed better control and less dramatic changes when reducing oxygen levels during weaning. ${ }^{21} \mathrm{Kuluz}$ and colleagues reported mean hypopharyngeal $\mathrm{F}_{\mathrm{IO}_{2}}$ of $>0.4$ when infants (age range 7-17 months) received oxygen flows exceeding $1 \mathrm{~L} / \mathrm{min}$. Some infants received $\mathrm{F}_{\mathrm{IO}_{2}}>0.8$ with flows as low as $2 \mathrm{~L} / \mathrm{min}$ (Fig. 3). Both the range and mean delivered $\mathrm{F}_{\mathrm{IO}_{2}}$ were reduced at oxygen flows $>1 \mathrm{~L} / \mathrm{min}$ if the infant's breathing frequency exceeded 40 breaths/min. ${ }^{22}$ Current American Association for Respiratory Care clinical practice guidelines make no statement with regard to delivered 


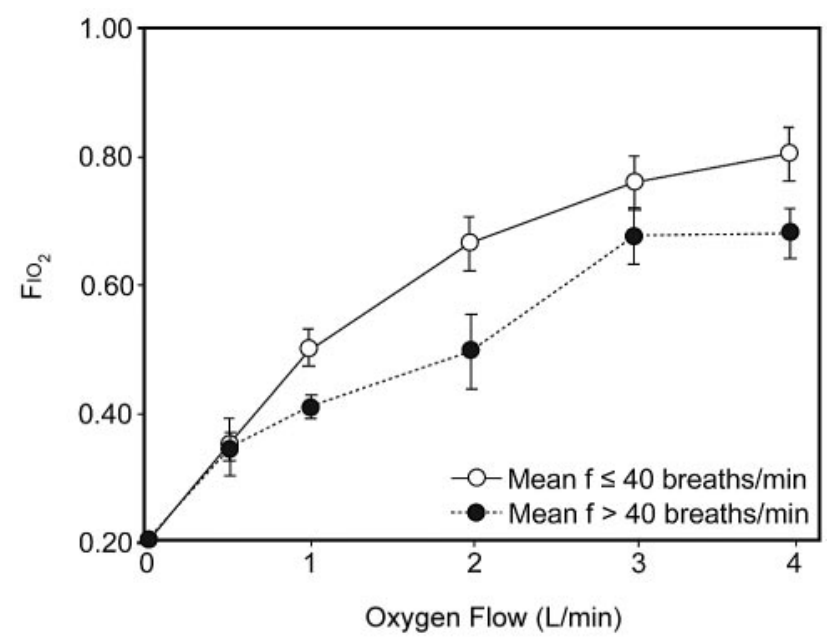

Fig. 3. Infant cannula $\mathrm{F}_{\mathrm{IO}_{2}}$ versus oxygen flow. $f=$ breathing frequency. (From Reference 22.)

$\mathrm{F}_{\mathrm{IO}_{2}}$ levels, yet note how they can be affected by both changes in $\dot{\mathrm{V}}_{\mathrm{E}}$ and the patient's inspiratory flow. However, the clinical practice guidelines do caution clinicians with regard to accuracy of low-flow flow meters and the potential for inadvertent CPAP, and therefore recommend maximum flow levels of $2 \mathrm{~L} / \mathrm{min} .^{23}$

\section{Physical and Anatomical Aspects Affecting Oxygen Delivery and Efficacy of the Nasal Cannula}

A number of the previously mentioned studies illustrated important points and problems for both researchers and clinicians attempting to predict $\mathrm{F}_{\mathrm{IO}_{2}}$ delivered via nasal cannulas. ${ }^{3,7,8}$ To objectively evaluate performance and potential efficacy, a number of variables must be either controlled for in research or considered when evaluating cannula systems in a real clinical setting (Table 3). Since the LFNC is an open system and by design is not intended to provide the entire inspired volume the patient inhales, room-air dilution (inboard leak) will alter the system's gas and the $\mathrm{F}_{\mathrm{IO}_{2}}$. With higher system flow, resident airway gas may be altered by incoming system gas during the expiratory phase.

The relationships of gas flow, oxygen concentration from the flow meter, and patient inspiratory flow pattern were discussed by Shigeoka and Bonekat in an editorial, and are illustrated in Figure 4; their equation identifies the nonlinear effect of those variables on delivered $\mathrm{F}_{\mathrm{IO}_{2}} \cdot{ }^{24}$ For that graphic the ratio of inspiratory time to total respiratory cycle time was set at 0.35 , and the ratio of dead space to tidal volume was fixed at 0.4 . The flow pattern during spontaneous breathing varies significantly and changes with inequality of inspiratory-expiratory ratio and degree of dyspnea. Although the inspiratory waveform during
Table 3. Variables in Evaluating Cannula Systems

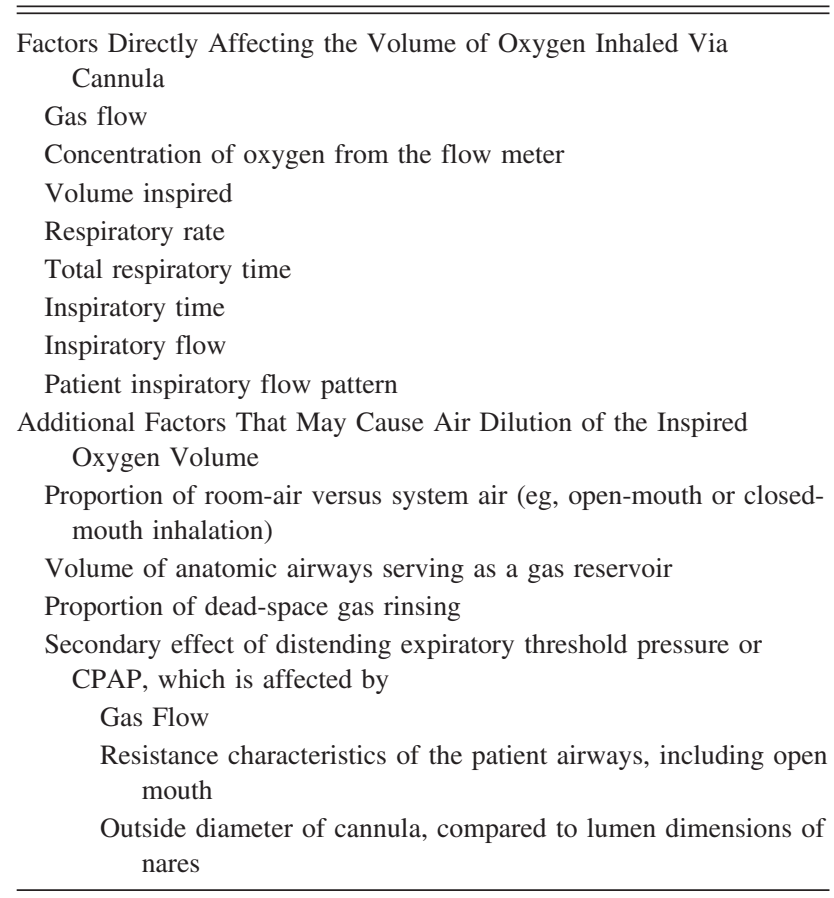

resting breathing does not conform to a half-sine wave, it closely approximates that pattern when spontaneous $\dot{\mathrm{V}}_{\mathrm{E}}$ increases. Equations predicting peak flow levels have been developed that may be useful in estimating inspiratory flow demand. ${ }^{25}$

The anatomy and geometry of the human nasal cavity, nasopharynx, and oropharynx should also be considered. A combination of oronasal breathing occurs in awake adults during speech and in response to exercise. Air flow profiles have been investigated in the past with in vitro models made using model casts from adult human cadavers. Hydrodynamic analysis of flow dynamics can be estimated based on visualizing smoke or radioactive tracers, small implanted Pitot tubes, or laser Doppler velocimetry. More recently mathematical models have been developed based on 3-dimensional computed tomography of the nose and computational fluid dynamic techniques. Results from these calculations appear to agree with human experimental data. ${ }^{26}$ The cross-sectional area of the nasal cavity can also be measured using acoustic rhinometry. In this technique an acoustic pulse is followed as it traverses each nasal cavity during an inspiratory cycle. ${ }^{27}$ Peak nasal inspiratory flow can be measured in human subjects using a peak flow meter with a mask. The following is a summary of pertinent findings that may relate to clinical aspects of HFNCs.

- Initial high-velocity inspiratory air flow passes through the lower half of the nasal cavity; this is primarily a respiratory function. The olfactory groove in the upper 


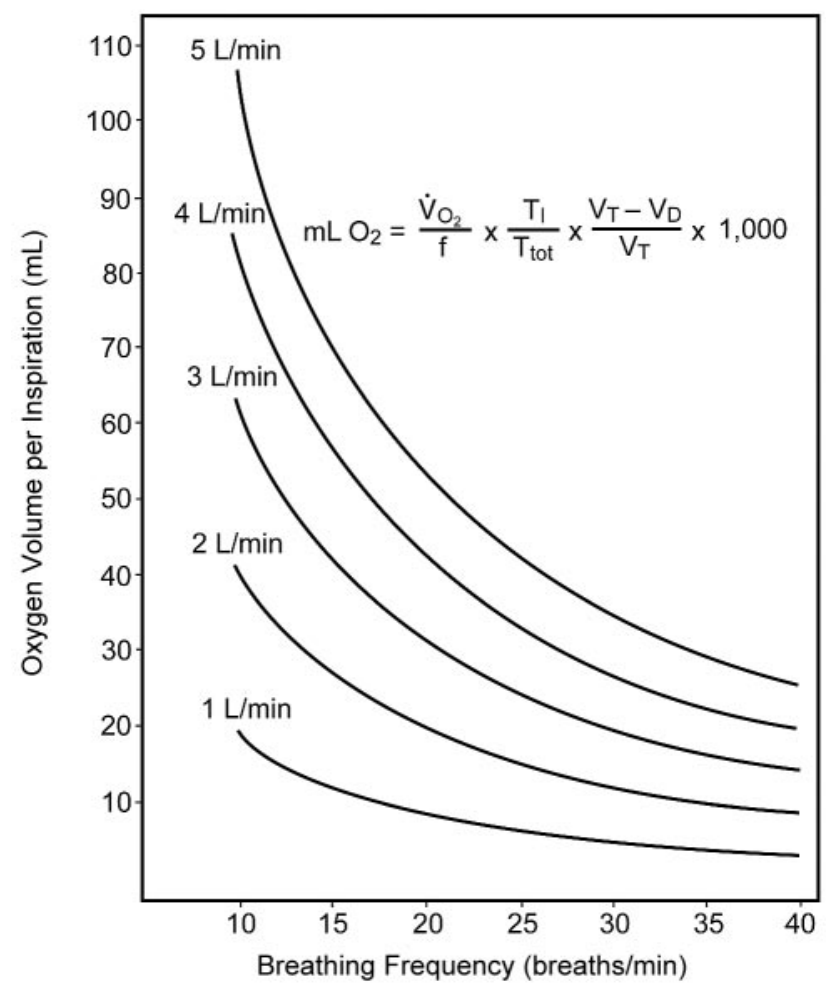

Fig. 4. Physical variables affecting $\mathrm{F}_{\mathrm{IO}_{2}}$ of nasal cannula with increasing breathing frequency (f), at flows from 1-5 L/min. Graphic and equation identify multiple factors that cause an exponential decline in volume of oxygen that can be inspired with increasing $\mathrm{f}$. Tidal volume $\left(\mathrm{V}_{\mathrm{T}}\right)$ and dead space $\left(\mathrm{V}_{\mathrm{D}}\right)$ were held constant. $\dot{\mathrm{V}}_{\mathrm{O}_{2}}=$ oxygen uptake. $\mathrm{T}_{\mathrm{I}}=$ inspiratory time. $\mathrm{T}_{\text {tot }}=$ total respiratory cycle time. (From Reference 24.)

portion of the nasal cavity receives lower velocity gas, yet flow is enhanced with sniffing.

- The anterior nasal cavity's functional nasal valve is the narrowest point of the nasal passage and major determinant of flow; this area is the flow limiting segment. The minimum cross-sectional area in adults is approximately $3 \mathrm{~cm}$ from the anterior naris.

- The posterior cavity is wider and circular; expiratory flow is directed along the turbinates.

- Nasal cavity volume and area have a linear relationship to flow; the nasal cavity does not directly follow the Poiseuille equation.

- Dynamic changes in nasal resistance may be affected by collapse of soft tissues as well as downstream resistance of the lower airways.

Differences in the newborn's nasal airway anatomy should also be considered.

- The nose is the preferred route, but is supplemented by oral breathing during sleep; the term "obligatory nasal breathers" has traditionally been used. ${ }^{28}$
- While feeding, a neonate's breathing is facilitated by the posterior tongue pressing upward on the soft palate to block the oral airway, which is referred to as the "veloglossal sphincter." This contributes to mouth breathing, requiring more coordination and creating higher resistance than only nasal breathing. ${ }^{29}$

- Primary oronasal breathing occurs normally with crying and returns to uninterrupted nasal or some combination of oronasal. When the nose is occluded, approximately $40-50 \%$ of normal term infants will quickly switch to oral breathing in 3-9 seconds; others require up to $30 \mathrm{sec}-$ onds. ${ }^{28}$

- There is a high level of resistance with oral breathing in preterm infants, which may limit effective breathing and result in obstructed efforts. Ability to adjust to sustained oral ventilation if nasal resistance or occlusion occurs is an important adaptive phenomenon in neonates and older infants. ${ }^{30}$

- A premature infant's skin is especially susceptible to injury from nasal mask prongs from nasal CPAP (NCPAP), or HFNC devices. Damage may occur at the nares, intranasal septum, the septum's anterior tip (columella), or philtrum. Both correct sizing and stabilization to prevent abrasion from device or tubing traction can minimize nasal lesions.

- In summary, the anatomy and nature of the nasal and nasopharyngeal airway of preterm, neonate, and infant babies suggests a complex pattern of resistance level and nose versus mouth breathing. There are also complex physical relationships in the adult airway, which result in changing dynamics on inspiration and exhalation. These factors may make bench or in vitro studies using resuscitation-type manikins difficult to apply to humans.

\section{Proposed Benefits of High-Flow Oxygen Via Cannula in Adult and Neonatal Care}

To improve the efficiency of the standard adult nasal cannula use at low flows, 2 approaches have been used to increase the volume of the inhaled oxygen bolus and reduce air dilution. The first technique was to attach storage reservoirs to the cannula. That approach was describe by Barach in $1960 .{ }^{31}$ Contemporary storage cannulas on those themes exist today but are largely relegated to ambulatory therapy. ${ }^{32,33}$ The alternative approach was to increase levels of gas flow to the cannula. Since the mid1960s respiratory care textbooks have cautioned directing flow $>6 \mathrm{~L} / \mathrm{min}$ with the cannula ${ }^{34,35}$; such recommendations continue. ${ }^{15}$ Reasons given include general patient discomfort, frontal sinus pain, as well as physical irritation and drying of nasal mucosa. The separate technical issue of humidification is a complicating factor. In current prac- 


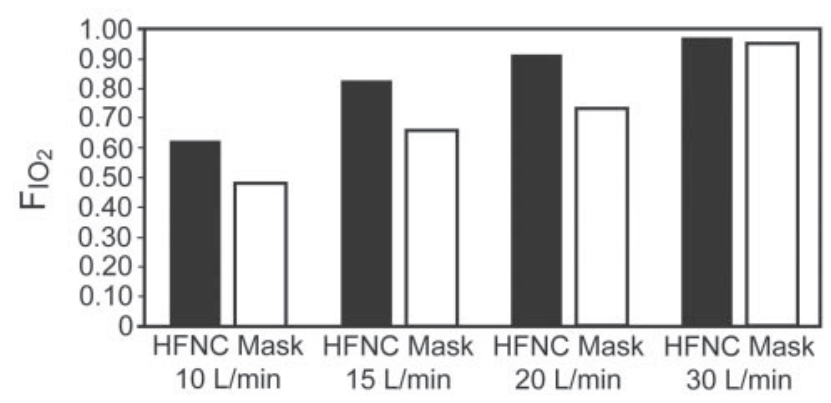

Fig. 5. Bench evaluation comparing $\mathrm{F}_{\mathrm{IO}_{2}}$ delivered by high-flow nasal cannula (HFNC) versus reservoir mask. Peak $\mathrm{F}_{\mathrm{IO}_{2}}$ levels measured at beginning of inspiration are plotted for Vapotherm HFNC versus non-rebreather $\mathrm{O}_{2}$ mask at 4 flows. The system combined an airway model with human subjects ventilation at a breathing frequency of 20 breaths/min. (From Reference 37.)

tice, oxygen at lower flows is either not humidified at all or is humidified with unheated "bubbler" humidifiers that do not meet recommended levels for the upper airway. ${ }^{36} \mathrm{In}$ 2002 the first abstracts appeared describing use of HFNC for adults, with flows of up to $40 \mathrm{~L} / \mathrm{min} .{ }^{37,38}$ In a bench study, normal subjects breathed with a breathing frequency of 20 breaths/min through an adult airway model. Tiep and Barnett observed ultrasonic fog to evaluate the function of the nasal cavity and upper airway as an oxygen reservoir. They also measured peak $\mathrm{F}_{\mathrm{IO}_{2}}$ with the Vapotherm HFNC system and compared it to a non-rebreather reservoir mask (NRB). They found the HFNC capable of delivering $\mathrm{F}_{\mathrm{IO}_{2}}$ of $0.62,0.82,0.9$, and 0.92 with flows of $10,15,20$, and $30 \mathrm{~L} / \mathrm{min}$, respectively (Fig. 5). ${ }^{37}$ Under such in vitro conditions, the cannula achieved higher $\mathrm{F}_{\mathrm{IO}_{2}}$ levels than a NRB bag mask at comparable oxygen flows. The authors postulated that the higher $\mathrm{F}_{\mathrm{IO}_{2}}$ levels were achieved due to high flow's limited inboard air dilution, and the nasopharynx and oropharynx acted as an (internal) anatomic reservoir that could increase the volume of inhaled oxygen for the subsequent inhalation. ${ }^{37}$ Using a cardiopulmonary-resuscitation-type manikin-airway and dual chambered test lung simulator, Malinowski and Lamberti found that an $\mathrm{F}_{\mathrm{IO}_{2}}$ of 0.83 could be achieved with a breathing frequency of 40 breaths/min, tidal volume of $0.5 \mathrm{~L}$, and $25 \mathrm{~L} / \mathrm{min}$ flow to the cannula. ${ }^{38}$

In 2004, a clinical study compared high-flow $40 \%$ oxygen delivered by Vapotherm humidifier to low-flow oxygen via mouthpiece during rest and exercise, using a nonrandomized comparison crossover study. Ten COPD patients with exercise limitation were studied as they exercised on a cycle ergometer. ${ }^{39}$ The authors found statistical improvement in $\mathrm{P}_{\mathrm{aO}_{2}}$ and $\mathrm{S}_{\mathrm{pO}_{2}}$ with the Vapotherm system with non-statistical improvement in duration of exercise and dyspnea index. They attributed these results to reduced room air entrainment, increased anatomical reservoir, and dead space washout effect. The authors sug- gested that the high-flow humidified gas might also be applied in clinical care as an intermediate device between traditional oxygen appliances and noninvasive ventilation (NIV). ${ }^{39}$ In 2004, a bench-study compared the humidification capability of 2 high-flow cannula systems; both achieved minimum recommended humidification levels, but the study did not evaluate oxygen delivery performance. ${ }^{40}$ In 2005, the performance of the Salter cannula and humidifier was studied in 10 normal subjects breathing at various breathing frequencies as well as during mouth closed versus open breathing. ${ }^{12}$ When $6-15 \mathrm{~L} / \mathrm{min}$ flows were used, pharyngeal sampling demonstrated mean $\mathrm{F}_{\mathrm{IO}_{2}}$ ranging from $0.54-0.75$ during normal resting nose breathing. $\mathrm{F}_{\mathrm{IO}_{2}}$ dropped slightly with increased breathing frequency but increased with mouth breathing. ${ }^{12}$

In contrast to the ability of higher flows to improve delivered oxygen concentrations to adults, the emphasis in perinatal care has been on higher flows creating CPAPlike distending pressures. Soon after the elucidation of the pathophysiology of infant RDS, Gregory et al described use of CPAP with intubated neonates to counteract atelectasis caused by surfactant deficiency. ${ }^{41}$ In the early 1990 s, CPAP-like distending pressure was demonstrated when premature neonates received higher flows using standard nasal cannula prongs. Locke and colleagues found that nasal cannulas $(0.2$ and $0.3 \mathrm{~cm}$ outer diameter $)$ could generate up to $9.8 \mathrm{~cm} \mathrm{H}_{2} \mathrm{O}$ at gas flows of $2 \mathrm{~L} / \mathrm{min}$. This positive pressure effect was felt to improve both oxygenation and thoraco-abdominal synchrony. They suggested careful prong size selection and cautioned against its indiscriminate use. ${ }^{42}$ In the mid and late 1970s studies were published that noted an additional therapeutic effect of NCPAP. Besides its treatment for RDS, NCPAP was found to affect respiratory control in newborns, as it decreased the number of central apneas (also known as apnea of prematurity) and subsequent bradycardia and oxygen desaturation; HFNC has been used as an alternative delivery device. ${ }^{43,44}$

HFNC therapy continues to be evaluated as an alternative nasal interface for newborns with RDS or as transition support immediately following extubation and mechanical ventilation.

The ability of HFNCs to also provide low level distending pressure to the upper airway of adults was documented a few years ago. ${ }^{45,46}$ In both studies, pressure measurement was performed by inserting catheters within the nasopharynx of normal subjects. In the Groves study, with HFNC flow of $40 \mathrm{~L} / \mathrm{min}$ and mouth closed, expiratory pressures ranged from 3.2-5.2 $\mathrm{cm} \mathrm{H}_{2} \mathrm{O} .{ }^{45} \mathrm{~A}$ representative pressure versus time scalar from the Parke et al study is shown in Figure 6. When the HFNC delivered $35 \mathrm{~L} / \mathrm{min}$, mean nasopharyngeal pressure (during the entire respiratory period) was found to be $2.7 \mathrm{~cm} \mathrm{H}_{2} \mathrm{O}$. Of note is that the pressure waveform dropped to zero during inspiration. 


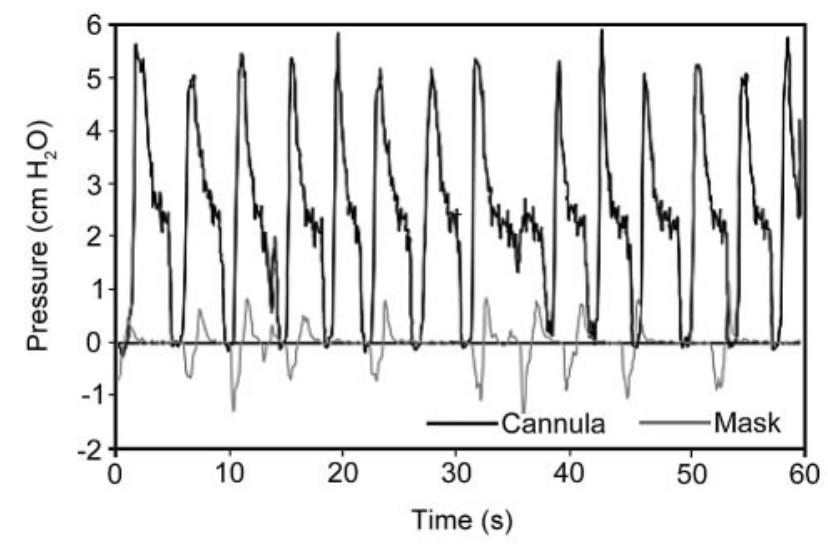

Fig. 6. Upper airway pressure versus time scalar of a subject using a high-flow nasal cannula. A nasopharyngeal cannula measured a mean pressure of approximately $2.7 \mathrm{~cm} \mathrm{H}_{2} \mathrm{O}$ (bold line). The cannula was set at $35 \mathrm{~L} / \mathrm{min}$ and the subject breathed with mouth closed. The gray line shows the pressure with an aerosol type face mask. (From Reference 46, with permission.)

Table 4. Summary of Proposed Effects That Determine Therapeutic Effects of High-Flow Nasal Cannula

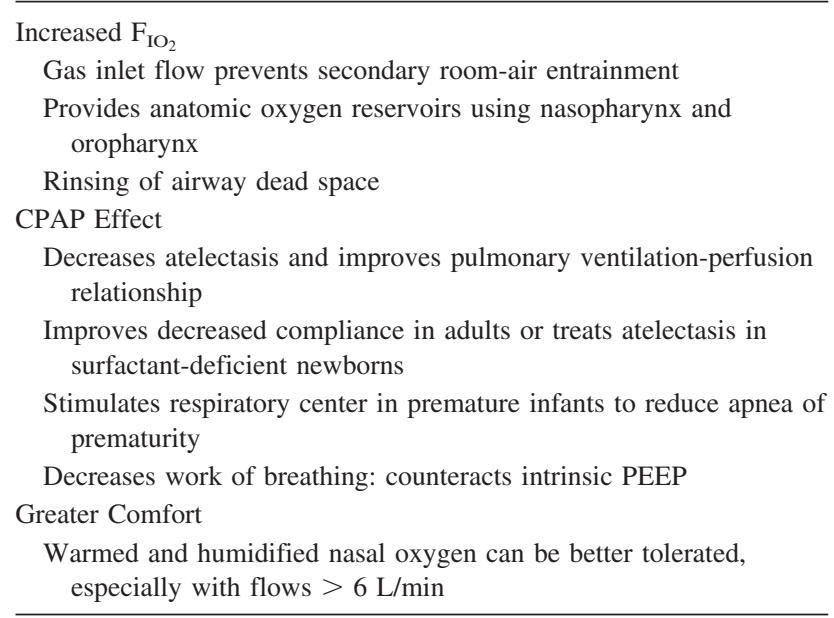

This documented a difference of the HFNC from an ideal CPAP delivery system. ${ }^{46}$ However, the HFNC's upper airway distending pressure was proposed to be transmitted to lower airways and alveoli to potentially benefit patients with either low pulmonary ventilation-perfusion regions causing hypoxemia and/or mechanical defect resulting from low functional residual capacity (Table 4).

In the past 5 years there has been increasing interest in the HFNC as an alternative oxygen delivery interface versus more established adult delivery devices such as NRB or masks, which use air-entrainment as part of large-volume aerosol nebulizer systems. In perinatal and pediatric care, besides oxygen delivery, the HFNC potential as an alternative NCPAP device has generated substantial research as to its application. A review of literature on the evaluation of the efficacy of both therapeutic approaches follows below.

\section{Equipment for Delivery of High-Flow Nasal Oxygen}

\section{HFNC for Adults}

A delivery system to provide HFNC oxygen requires 3 components: a patient interface, a gas delivery device(s) to control flow and $\mathrm{F}_{\mathrm{IO}_{2}}$, and a humidifier. An adult nasal cannula with standard dimension prongs can accommodate high inlet flow of at least $60 \mathrm{~L} / \mathrm{min}$. Several manufacturers provide cannulas of similar style and appearance, which are designated for high-flow applications (Fig. 7). The Fisher \& Paykel OptiFlow cannulas use a different design. The nasal prongs are held in place on the upper lip with an elastic over-ear head band. There is a larger diameter flex tubing proximal to the prongs and an aroundthe-neck elastic that connects to support the weight of the connecting tubing (see Fig. 7D). They are available in large, medium, and small sizes, with oval shaped prong orifices measuring approximately $6.5 \mathrm{~mm}$ outer diameter and $4 \mathrm{~mm}$ outer diameter, respectively (see Fig. 7E).

Medical gas for LFNCs is commonly provided by a $(0-5$ or $0-16 \mathrm{~L} / \mathrm{min})$ calibrated oxygen flow meter. To accommodate higher flows, commercially available calibrated high-flow $(0-70 \mathrm{~L} / \mathrm{min})$ oxygen flow meters can be applied. To allow independent adjustment of $\mathrm{F}_{\mathrm{IO}_{2}}<1.0$, separate high-flow air and $\mathrm{O}_{2}$ flow meters can be connected via a "Y-piece" adapter. To allow more convenient application, high-flow air $/ \mathrm{O}_{2}$ proportioner valve blenders or high-flow "Venturi" air mixing valves can be used. With either approach, an oxygen analyzer is needed to confirm accurate air $/ \mathrm{O}_{2}$ mixing.

A key element for clinical use of nasal oxygen at high flow is effective humidification. Supplemental water vapor is not commonly provided for low flows, $\leq 2-3 \mathrm{~L} / \mathrm{min}$. There has been a tradition of humidification for flows $>5-6 \mathrm{~L} / \mathrm{min}$. Unheated bubble-type humidifiers have been used in spite of both lack of evidence of overall efficacy and decreasing efficiency of humidification as flows increased. 15,16,47 Minimum water content for low-flow cannula use has not been defined. When patients breathe dry oxygen from a nasal cannula, additional water vapor is entrained with room air from their environment. This would vary significantly depending on both temperature and relative humidity. The ASTM International (formerly the American Society for Testing and Materials) recommends a minimum absolute humidity of $10 \mathrm{mg} \mathrm{H}_{2} \mathrm{O} / \mathrm{L}$ for gas that does not bypass the upper airway. This would approximate a relative humidity of $50 \%$ at $22^{\circ} \mathrm{C}$, which reflects normal environmental conditions. ${ }^{48}$

In early 2000, the first 2 commercial adult HFNCs appeared, which were promoted to deliver flows $>10 \mathrm{~L} / \mathrm{min}$ 

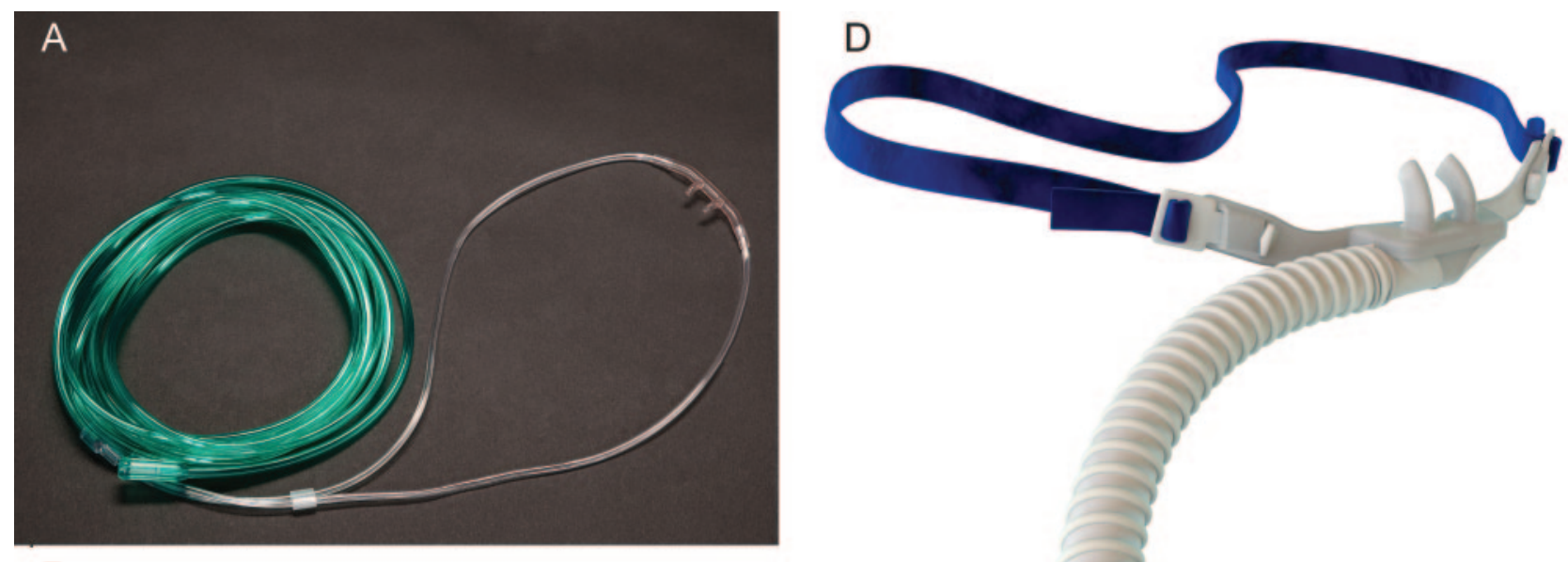

B
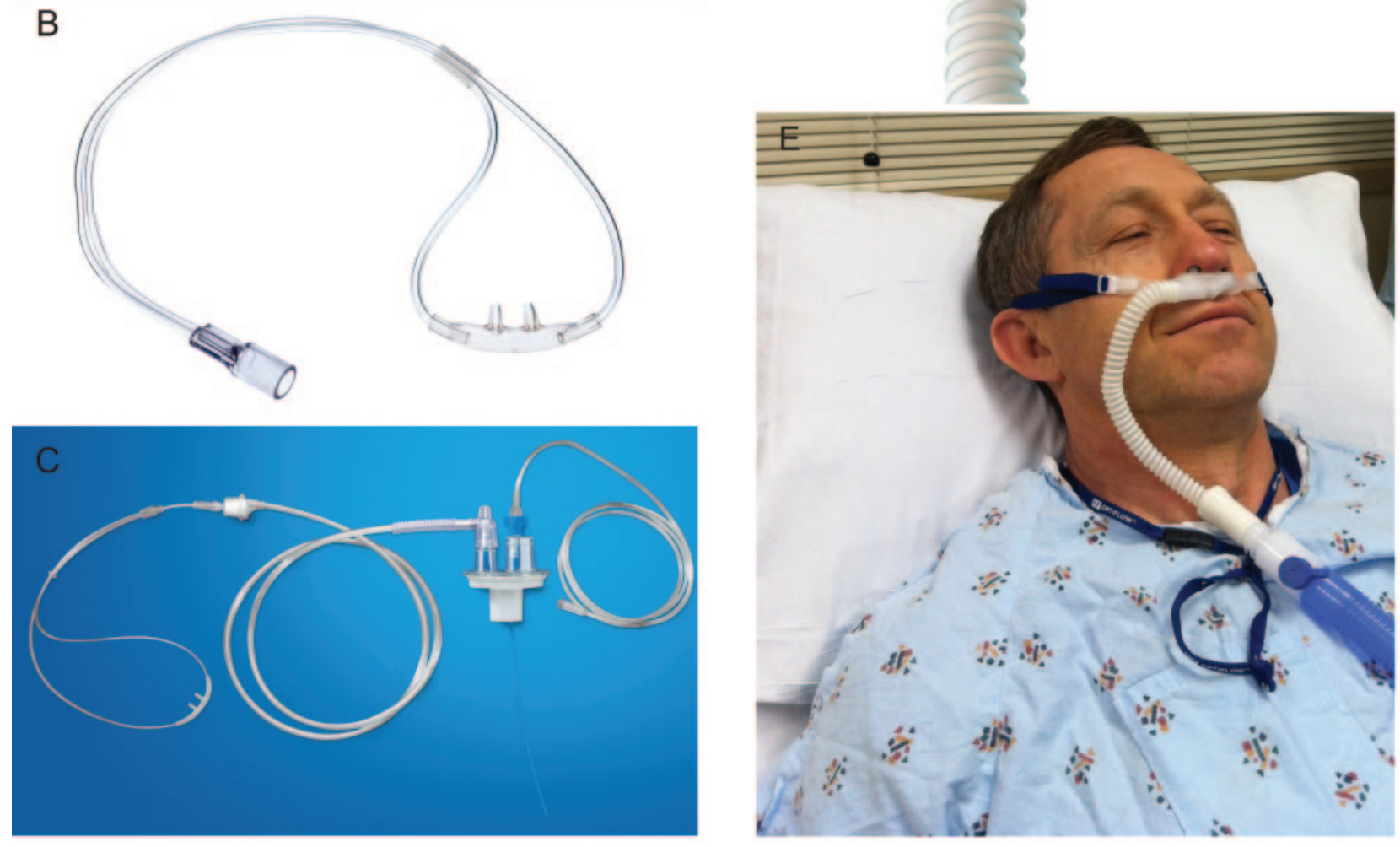

Fig. 7. Examples of adult high-flow nasal cannulas. A: Salter Labs 1600HF high-flow adult cannula. (Courtesy of Salter Labs.) B: Comfort Flo. (Courtesy of Teleflex Medical.) C: Aquinox high-flow cannula. (Courtesy of Smiths Medical.) D: OptiFlow adult cannulas. (Courtesy of Fisher \& Paykel.) E: OptiFlow high-flow adult cannula on an adult patient.

with accompanying humidifiers. Salter Labs produced a high-flow (unheated) bubble humidifier (Fig. 8). It resembles a low-flow bubbler design. The diffuser's design is touted to allow reduced resistance; standard narrow bore tubing is used en route to the cannula, and meets minimum humidity standards when used at flows up to $15 \mathrm{~L} / \mathrm{min}$. That maximum flow capability is on the lower end of other commercial adult HFNC systems. About the same time, Vapotherm developed the 2000i High-Flow Therapy system, which consisted of a designated cannula with a heated cartridge-type humidifier using membrane technology for water vapor transfer (see Fig. 8B). Flow capacity with adequate humidification was advertised up to $40 \mathrm{~L} / \mathrm{min}$; the system requires a separate air $/ \mathrm{O}_{2}$ blender and flow meter. A 2004 bench study reviewed both systems for the capability to provide humidification over the manufacturers' recommended flows for clinical use. ${ }^{38}$ The Salter device's relative humidity levels at ambient temperature $\left(21-23^{\circ} \mathrm{C}\right)$ ranged from $76.9 \pm 5.8 \%$ and $78.7 \pm 4.6 \%$ at flows of 10 and $15 \mathrm{~L} / \mathrm{min}$, respectively. The Vapotherm system achieved close to $100 \%$ relative humidity with the heated system operating at $36.5^{\circ} \mathrm{C} .3^{38}$ The Vapotherm $2000 \mathrm{i}$ 
A
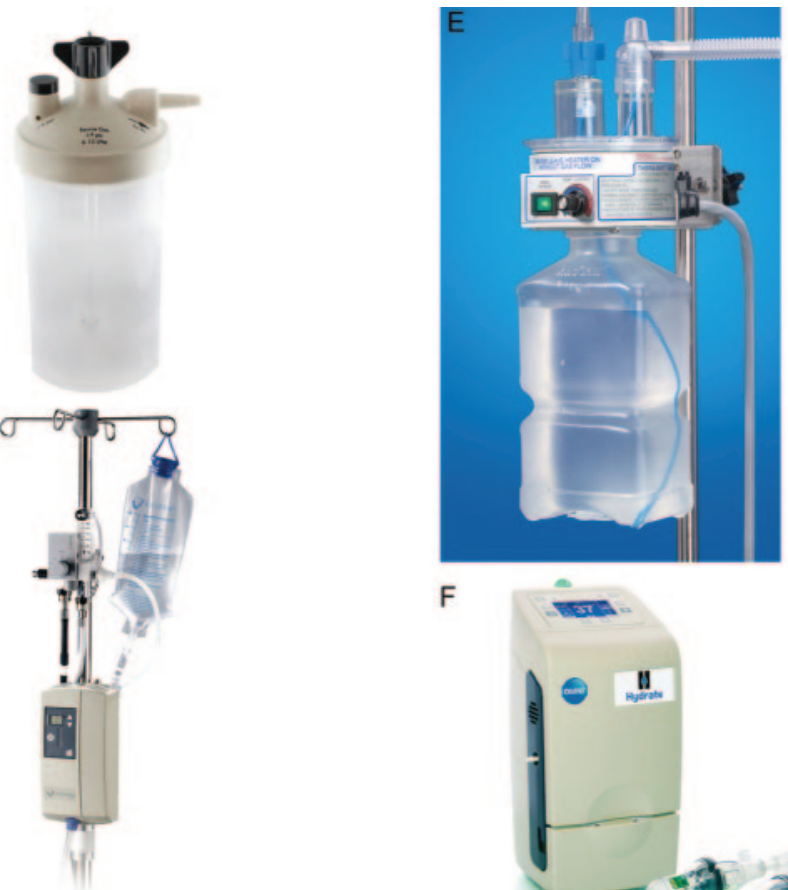

B

C
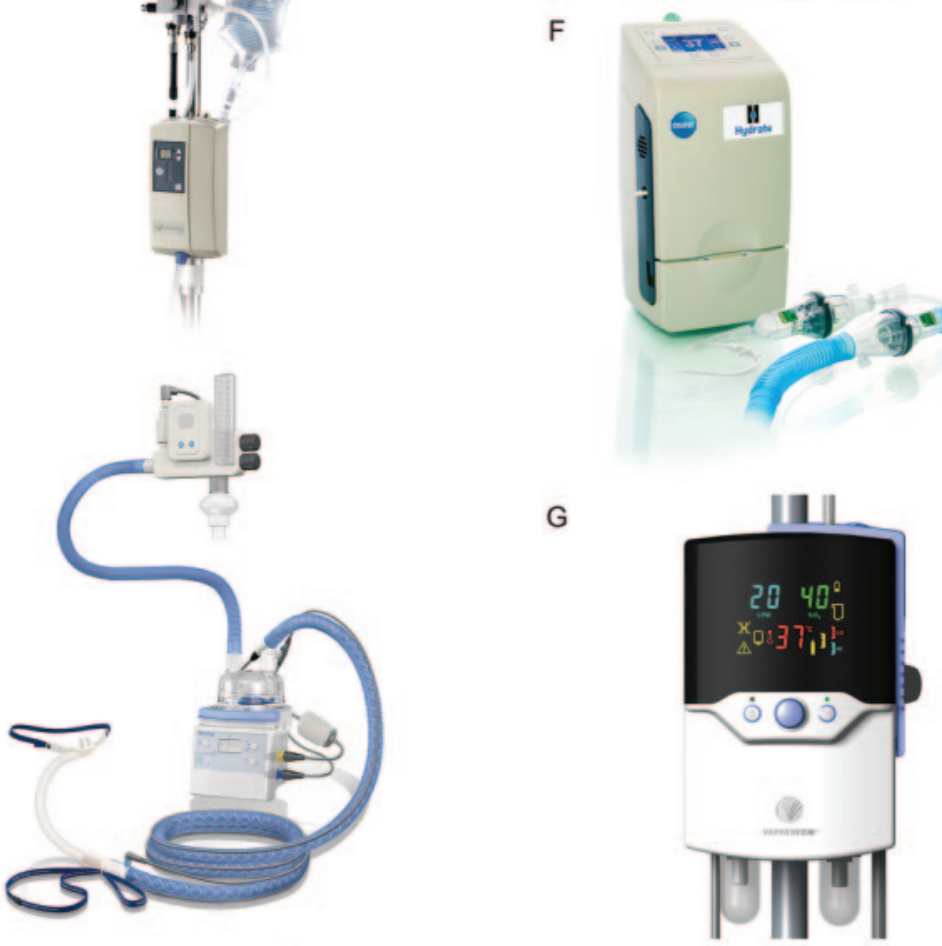

D

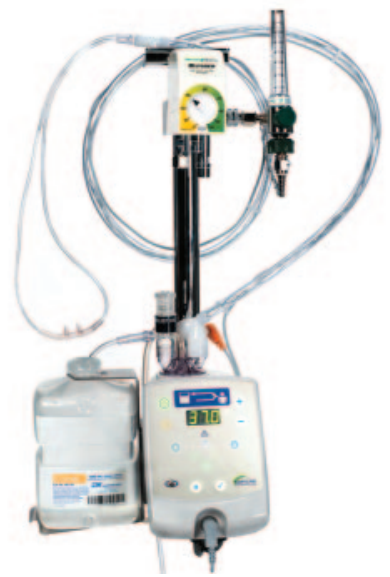

Fig. 8. Humidification systems for high-flow cannulas. A: High-flow bubble humidifier. (Courtesy of Salter Labs.) B: Vapotherm 2000i heated humidifier with continuous feed system and high-flow air/O $\mathrm{O}_{2}$ blender (BL S2001-HF) with click-style flow meter (FM40). (Courtesy of Vapotherm.) C: Fisher \& Paykel 850 heated humidifier (Courtesy of Fisher \& Paykel) and Maxtec MaxVenturi combination $\mathrm{O}_{2} /$ air entrainment device, oxygen analyzer, and flow meter with single-limb heated-wire circuit. D: Comfort Flo humidification system. (Courtesy of Teleflex Medical.) E: Aquinox high-flow humidification system. (Courtesy of Smiths Medical.) F: Pari Hydrate humidification system for high-flow nasal cannula. (Courtesy of Pari Respiratory Equipment.) G: Vapotherm Precision Flow humidification system. (Courtesy of Vapotherm.) 
was recalled in 2005 due to concerns of bacterial contamination, but was reinstated after manufacturing controls and recommendations for use of only sterile water, singlepatient use, and disinfection procedures. ${ }^{49}$

The Fisher \& Paykel OptiFlow HFNC became commercially available in 2006 (see Fig. 8C). The system uses a heated humidifier with hot-plate and single-use water chamber, similar to those for application for noninvasive or invasive mechanical ventilation. A separate or combined air $/ \mathrm{O}_{2}$ blender or air-oxygen entrainment device and flow meter provide oxygen mixtures with flow $\geq 40 \mathrm{~L} /$ min. An oxygen analyzer is also required. Humidified gas mixtures exit the humidifier through large bore corrugated tubing that connects to the cannula with a $15 \mathrm{~mm}$ outer diameter adapter. A heated-wire circuit is used to minimize condensation to prevent liquid water from potentially obstructing the HFNC. Flow continues through an $18 \mathrm{~cm}$ length of $10 \mathrm{~mm}$ outer diameter flex tubing and finally to the cannula. In the past few years other manufacturers have developed similar systems. The Teleflex Comfort Flo humidification system was made available in 2006. It incorporates a cartridge-humidifier and is designed to accommodate continuous gas flow up to $40 \mathrm{~L} / \mathrm{min}$ (see Fig. 7D). The Smiths Medical Aquinox high-flow humidification system allows humidification up to $35 \mathrm{~L} / \mathrm{min}$ (see Fig. 8E). Both of the latter 2 devices require adjunct oxygen/air blenders and flow meters. The Pari Hydrate humidifier was approved in 2007 for clinical use, including HFNC applications (see Fig. 8F).

In 2008 Vapotherm released its Precision Flow highflow humidification system (see Fig. 8G). It is similar to the $2000 \mathrm{i}$, as it uses a cartridge-like humidifier. This model differs from the Vapotherm 2000i and the other commercial systems as the air/ $\mathrm{O}_{2}$ blender and oxygen analyzer are integrated within the humidifier module.

Because of the need to provide independent control of oxygen concentration and a heated humidifier, the acquisition cost of an HFNC system is substantially higher than for a typical LFNC system. Purchase cost for a commercial HFNC system (stand, blender/flow meter/analyzer, humidifier, heated-wire circuit, and cannula) is approximately $\$ 2,600$. A less expensive alternative system could be assembled if air and $\mathrm{O}_{2}$ high-flow $(0-70 \mathrm{~L} / \mathrm{min})$ flow meters were substituted for the air/ $\mathrm{O}_{2}$ blender-flow meter and already available oxygen analyzer, and humidifier were used. In addition to free-standing humidified high-flow blenders, there are some current mechanical ventilators that can also serve as sources for continuous flow of humidified blended gas for HFNCs.

\section{HFNC Equipment for Newborn and Infants}

As was mentioned previously, the clinical application of nasal cannula oxygen with flow $>1 \mathrm{~L} / \mathrm{min}$ applied to premature babies, newborns, and pediatric patients had an earlier and slightly different evolution than with adults. A number of patient interfaces were initially developed for NCPAP, including head-hood or facial chamber, sealing face or nasal mask, and long nasopharyngeal tube. Currently NCPAP is most commonly applied using short binasal pharyngeal prongs, with humidified gas source and circuit. A recent Cochrane Collaboration analysis literature review has suggested that short bi-nasal prongs are more effective than the nasopharyngeal tubes. They noted that the literature is not clear on the optimal pressure generating source. ${ }^{50}$ Of key importance with NCPAP nasal prongs is correct sizing, as they are designed to seal within the nares to maintain constant pressure. Attachment and fixation of the prongs is commonly accomplished by head cap. Caps permit prongs to be placed so that they either avoid touching or gently rest on the columella and minimize abrasion from movement of the child or traction from tubing. NCPAP nasal injuries from prongs and masks are common and have been documented in the past. They can range from hyperemia to necrosis and result in permanent damage. ${ }^{51,52}$ The most important independent risk factor for complications is duration of NCPAP use. ${ }^{53}$

As was noted previously, an NCPAP-like effect has been recognized when using (non-sealing) nasal cannulas at higher flows. ${ }^{42,54}$ Equipment includes nasal cannulas with a number of sizing options. Figure 9 identifies 2 examples of commercially available perinatal nasal cannulas for high-flow application. Manufacturers typically identify the outer diameter of prong, and septum width; maximum patient flow is usually recommended. For both premature and newborns, prong diameter is approximately $2.4 \mathrm{~mm}$ outer diameter; septum width is $2.5 \mathrm{~mm}$ for premature and $3.5 \mathrm{~mm}$ for neonates. Infant and pediatric prong diameters would be approximately $2.4-3.7 \mathrm{~mm}$ outer diameter, and septum widths vary from 4.5 to $8 \mathrm{~mm}$. Methods to create distending pressure include underwater column (also known as bubble CPAP) or flow generator with inspiratory-expiratory switching valve. The humidification systems used include those previously identified for HFNC for adults. An example of a Fisher \&Paykel system is shown in Figure 10A. Blended air/oxygen mixtures are provided by flow meters capable of accurately indicating actual flow in low ranges $(\approx 1-5 \mathrm{~L} / \mathrm{min})$. Heated-wire circuits are commonly used to reduce the potential for condensate formation and liquid water from reaching the nasal prongs. Because of their distending pressure effect, it is important that systems have some method to prevent high pressure from either unexpected increases in downstream resistance or inadvertent increase in delivered flow (see Fig. 10B). The Vapotherm Precision Flow device uses sensors to detect downstream obstruction, which causes an audio alarm and visual alert. 
A
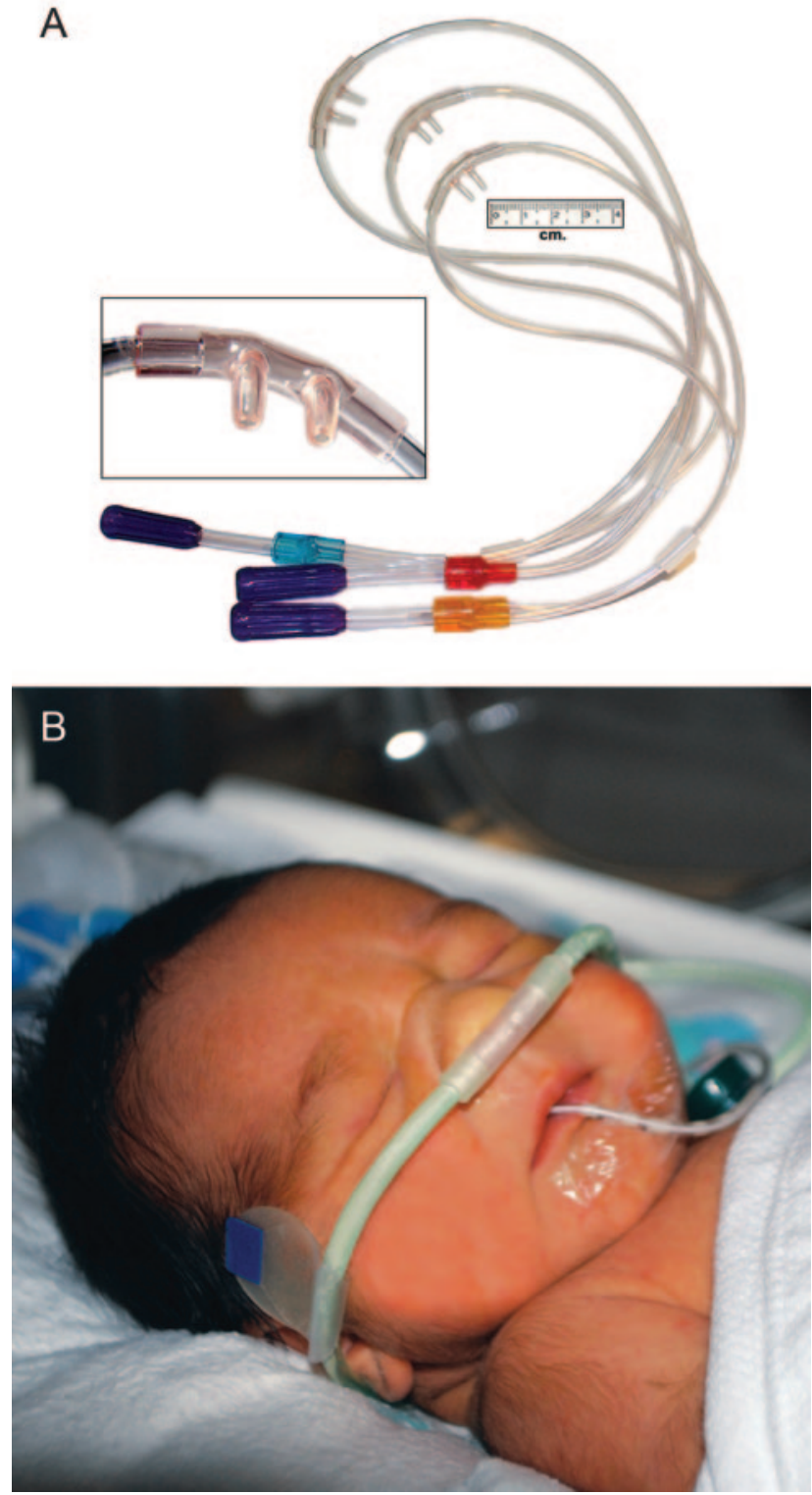

Fig. 9. Examples of perinatal high-flow cannulas. A: Fisher \& Paykel premature, neonatal, and intermediate infant cannulas. (Courtesy of Fisher \& Paykel.) B: Neotech RAM cannula. (Courtesy of Neotech.)

\section{Randomized or Quasi-Randomized Trials of HFNC for Adult Patients}

The major objective of published evaluations of adult HFNCs has targeted its ability to provide enriched oxygen to hypoxemic patients. The reports have included bench study simulations and patient investigations, many published only in abstract form.

Several peer-review published summaries have also included abstracts in their analysis of evidence. ${ }^{55,56}$ There are also several published papers that were conducted with normal healthy adult volunteers to specifically quantify
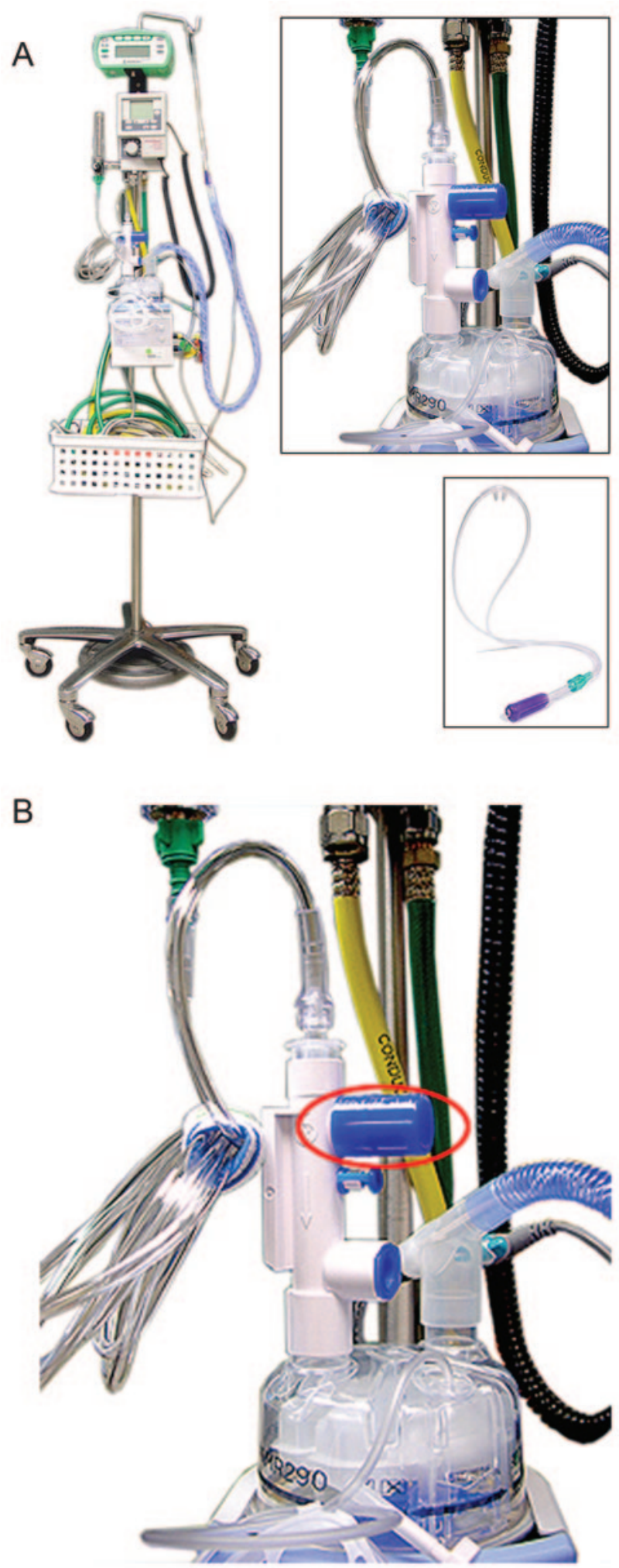

Fig. 10. A: Example of a perinatal high-flow nasal cannula system. $\mathrm{B}$ : Detail showing pressure-relief valve. 


\section{High-Flow Oxygen Administration by Nasal Cannula for Adult and Perinatal Patients}

the capability to generate positive airway pressure. ${ }^{45,46}$; one was in the form of a case study. ${ }^{57}$

All 3 studies measured pressure via pressure transducer fitted to nasopharyngeal catheters. Groves and Tobin varied HFNC flow from 10-60 L/min and measured pressures when the mouth was closed and open. With closed mouth, mean pharyngeal pressures rose linearly from 3.7, 7.2, and $8.7 \mathrm{~cm} \mathrm{H}_{2} \mathrm{O}$ at flows of 20,40 , and $60 \mathrm{~L} / \mathrm{min}$, respectively. With mouth open, pressures fell to $1.4,2.2$, and $2.7 \mathrm{~cm} \mathrm{H}_{2} \mathrm{O}$ at the same flow levels. ${ }^{45}$ The Parke group maintained a constant $35 \mathrm{~L} / \mathrm{min}$ flow and found mean pressure to be $2.7 \mathrm{~cm} \mathrm{H}_{2} \mathrm{O}$ with mouth closed and $1.2 \mathrm{~cm} \mathrm{H}_{2} \mathrm{O}$ when mouth open. ${ }^{46}$

In the recent past there have been an increasing number of clinical studies that have potential to guide clinicians in use of HFNC systems. A brief summary of 7 selected studies will follow and note key findings and limitations. The following criteria were used for their selection:

- Studies not published in peer-reviews journals or abstracts were excluded.

- In vitro bench studies (mostly with manikins) were excluded.

- Normal human and animal studies were excluded.

- Studies that did not have a measurable outcome related to oxygen therapy were excluded.

- Studies that did not provide adequate technical details of the oxygen delivery systems used (eg, brand/model of devices, $\mathrm{F}_{\mathrm{IO}_{2}}$ settings, or gas flow levels) were excluded.

A chronological review of the selected studies with discussion will follow; Table 5 provides a summary. ${ }^{39,58-63}$ In 2004 Chatila and colleagues investigated Vapotherm humidified high-flow (25 L/min) blended oxygen during rest and exercise with COPD patients. ${ }^{39}$ The authors set up a crossover comparison with low flow oxygen. Their hypothesis was that the high flow and humidification of the Vapotherm device would provide improved oxygenation during exercise and reduce discomfort of nasal dryness. Although the humidifier was used, nasal cannulas were not worn by patients; gas was supplied to a mouthpiece as part of a pneumotachograph. Although a small study and not randomized to sequence of high or low flow, the authors did document statistical significance in $\mathrm{P}_{\mathrm{aO}_{2}}$ and $\mathrm{S}_{\mathrm{pO}_{2}}$ during 12 min cycle ergometer exercise, as well as duration of exercise with the high-flow Vapotherm. There was nonstatistical improvement in breathing frequency, breathing frequency/tidal volume ratio, and inspiratory time/total breathing time ratio. Differences were seen even though the $\mathrm{F}_{\mathrm{IO}_{2}}$ for low-flow oxygen was adjusted to the equivalent $0.4 \mathrm{~F}_{\mathrm{IO}_{2}}$ of the high-flow system, which was set at $20 \mathrm{~L} / \mathrm{min}$. The study found no differences in $\dot{V}_{\mathrm{E}}$, tidal volume, or work of breathing. It served only to suggest that high flow is probably better than low flow during periods when patients require high inspiratory flow. One limitation to applying these data was that oxygen delivery was not directly provided by nasal interface. ${ }^{39}$

In 2008 Price and coauthors performed a retrospective 2-year audit of 72 patients who received care in an Australian hospital's postoperative surgical high-dependence unit. Fifty-five of the subjects had a diagnosis of "type I" hypoxemic respiratory failure. ${ }^{58}$ The audit was done as the Vapotherm humidified HFNC had been newly added as an oxygen delivery system. The purpose of the study was to evaluate performance and identify problems and general level of acceptance by both patients and staff. $\mathrm{HFNC} \mathrm{O}_{2}$ therapy was initiated after baseline ABGs and other vital signs were recorded. The average pre-trial baseline $\mathrm{P}_{\mathrm{aO}_{2}}$ was $61 \pm 13 \mathrm{~mm} \mathrm{Hg}$, and $\mathrm{S}_{\mathrm{aO}_{2}} 89.7 \pm 5 \%$. One hour after HFNC therapy (flow was 20-35 L/min), the average $\mathrm{P}_{\mathrm{aO}_{2}}$ increased to $93 \pm 43.7 \mathrm{~mm} \mathrm{Hg}$ and $\mathrm{S}_{\mathrm{aO}_{2}}$ to $94.55 \pm 3.6 \%$. However, precise performance analysis was limited, as the flow and $\mathrm{F}_{\mathrm{IO}_{2}}$ of the HFNC systems were individually titrated to the patient, the latter ranging from 0.6 to 1.0 with an average of $0.81 \pm 0.21$. The authors also noted a modest reduction in average breathing frequency, from $26.27 \pm 7.1$ to $22.57 \pm 6.13$ breaths $/ \mathrm{min}$. There were no changes noted in $\mathrm{P}_{\mathrm{aCO}}$ or $\mathrm{pH}$. Ten of the 72 patients later required intubation and mechanical ventilation, but this could not be compared to historical data. Patient satisfaction with HFNC was rated at $90 \%$ positive, but not based on comparison to other oxygen therapy or analysis of dissatisfaction. The paper concluded that the HFNC could provide oxygen that was adaptable to post-surgical patients and was well accepted by staff. ${ }^{58}$

In 2010 Tiruvoipati and colleagues performed a prospective randomized crossover trial of 50 patients who required high-flow supplemental oxygen following extubation. ${ }^{59}$ The objective was to compare efficacy of the HFNC to high-flow oxygen delivered by mask in terms of gas exchange; secondary effects on vital signs, comfort, and patient tolerance were also studied. The Fisher \& Paykel OptiFlow cannula was randomized to high-flow face mask therapy (not identified). During a 30-min post-extubation stabilization period, $\mathrm{F}_{\mathrm{IO}_{2}}$ was titrated to achieve desired oxygen saturations. Blind randomization identified patients for either HFNC or face mask system for $30 \mathrm{~min}$, at the end of which vital signs were obtained. Patients then were switched to the alternate system and data collection repeated. Both oxygen delivery devices provided $30 \mathrm{~L} / \mathrm{min}$ total flow, and $\mathrm{F}_{\mathrm{IO}_{2}}$ matched those required during the initial stabilization period. Comfort was evaluated by nurse interview, using a visual analog scale. Tolerance, or exit criteria, was based on observation of worsening respiratory, cardiovascular, and central nervous system signs. Results identified no statistically significant differences in gas exchange or vital signs. There was a statistically sig- 


\section{High-Flow Oxygen Administration by Nasal Cannula for Adult and Perinatal Patients}

Table 5. Summary of Published Clinical Studies on Use of HFNC in Adults

\begin{tabular}{|c|c|c|c|c|c|}
\hline First Author & Year & Type of Study and HFNC Device & Number of Participants and Setting & Outcomes & Comments \\
\hline Chatila $^{39}$ & 2004 & $\begin{array}{l}\text { Non-randomized crossover. } \\
\text { Vapotherm humidifier with } \\
20 \mathrm{~L} / \mathrm{min} \text { flow } \mathrm{O}_{2} \text { with } \\
\mathrm{F}_{\mathrm{IO}_{2}} 0.4 \text { vs non-humidified } \\
\text { low-flow oxygen }(2.5-6 \mathrm{~L} / \mathrm{min} \\
\mathrm{F}_{\mathrm{IO}_{2}} \text { of } 0.39 \pm 0.01\end{array}$ & $\begin{array}{l}10 \text { stable COPD patients, mean } \\
\mathrm{FEV}_{1} / \mathrm{FVC} 30 \pm 9 \% \\
\mathrm{FEV}_{1} 23 \pm 6 \%, \text { out-patient } \\
\text { clinic }\end{array}$ & $\begin{array}{l}\text { Significant improvement } \\
(P<.001) \text { in } \mathrm{P}_{\mathrm{aO}_{2}} \text { and } \mathrm{S}_{\mathrm{pO}_{2}} \\
\text { during } 12 \text { min of cycle } \\
\text { ergometer exercise } \\
\text { No significant improvement in } \\
\mathrm{P}_{\mathrm{aO}_{2}} \text { and } \mathrm{S}_{\mathrm{pO}_{2}} \text { at rest, } \\
\text { dyspnea score during } \\
\text { exercise, and length of } \\
\text { exercise with low flow }\end{array}$ & $\begin{array}{l}\text { Nasal cannulas were not worn by } \\
\text { either group. } \mathrm{O}_{2} \text { administered } \\
\text { by mouthpiece. } 8 / 10 \text { patients } \\
\text { had full data sets. } 5 / 10 \text { were } \\
\text { able to complete both } 12 \text {-min } \\
\text { exercise periods. } 3 / 10 \text { required } \\
\text { low-flow to be increased from } \\
\text { mean of } 2.8 \pm 0.3 \mathrm{~L} / \mathrm{min} \text { to } \\
9.6 \pm 6.5 \mathrm{~L} / \mathrm{min} \\
\text { Evaluated high flow of heated } \\
\text { humidified gas } \\
\text { No perceived conflict of interest }\end{array}$ \\
\hline Price $^{58}$ & 2008 & $\begin{array}{l}\text { Prospective 2-year audit of } \\
\text { HFNC Vapotherm device }\end{array}$ & $\begin{array}{l}72 \text { patients in surgical high- } \\
\text { dependency unit } \\
77.5 \% \text { with hypoxemic respiratory } \\
\text { failure }\end{array}$ & $\begin{array}{l}\text { No significant improvements in } \\
\text { baseline } \mathrm{P}_{\mathrm{aO}} \text {, arterial } \\
\text { oxygen saturation, or } \\
\text { breathing frequency } \\
90 \% \text { patient general } \\
\text { satisfaction }\end{array}$ & $\begin{array}{l}\text { Staff found system more } \\
\quad \text { adaptable than previous device } \\
\text { Maximum } \mathrm{F}_{\mathrm{IO}_{2}} 0.6-0.85 \\
\text { No perceived conflict of interest }\end{array}$ \\
\hline Tiruvoipati $^{59}$ & 2010 & $\begin{array}{l}\text { Prospective randomized crossover } \\
\text { trial of Optiflow HFNC vs } \\
\text { high-flow face mask matched } \\
\text { for flow and } \mathrm{F}_{\mathrm{IO}_{2}}\end{array}$ & $\begin{array}{l}50 \text { patients requiring supplemental } \\
\mathrm{O}_{2} \text { post extubation }\end{array}$ & $\begin{array}{l}\text { No significant differences in } \\
\text { gas exchange criteria or vital } \\
\text { signs } \\
\text { Positive trend for HFNC in } \\
\text { comfort (visual analog } \\
\text { scale), tolerance, and } \\
\text { reduced requirement to exit } \\
\text { trial due to worsening } \\
\text { physiologic signs }\end{array}$ & $\begin{array}{l}\text { High-flow mask system was not } \\
\text { identified by brand/type } \\
\text { No perceived conflict of interest }\end{array}$ \\
\hline $\operatorname{Roca}^{60}$ & 2010 & $\begin{array}{l}\text { Prospective sequential } \\
\text { intervention } \\
\text { Face mask with low-flow nasal } \\
\text { oxygen, followed by Optiflow } \\
\text { HFNC }\end{array}$ & $\begin{array}{l}50 \text { patients who failed to increase } \\
\mathrm{S}_{\mathrm{pO}_{2}} \text { to }>97 \% \text { on low-flow } \\
\text { nasal cannula }+\mathrm{O}_{2} \text { face mask } \\
\text { with } \mathrm{F}_{\mathrm{IO}_{2}} \geq 0.5\end{array}$ & $\begin{array}{l}\text { Significant differences: } \mathrm{P}_{\mathrm{aO}} \\
\text { and } \mathrm{S}_{\mathrm{pO}_{2}} \text { increased and } \\
\text { breathing frequency declined } \\
\text { with HFNC } \\
\text { Subjective assessment of } \\
\text { comfort favored HFNC }\end{array}$ & $\begin{array}{l}\text { Delivered } \mathrm{F}_{\mathrm{IO}_{2}}\left(\mathrm{HFNC} \text { and } \mathrm{O}_{2}\right. \\
\text { mask) were based on } \\
\text { manufacturer specifications } \\
\text { and not measured } \\
\text { Total flow from the HFNC and } \\
\text { low-flow nasal cannula }+ \\
\text { mask were not equal } \\
\text { No perceived conflict of interest }\end{array}$ \\
\hline Parke $^{61}$ & 2011 & $\begin{array}{l}\text { Prospective randomized trial of } \\
\text { Optiflow HFNC vs air- } \\
\text { entrainment face mask }\end{array}$ & $\begin{array}{l}60 \mathrm{ICU} \text { patients with mild to } \\
\text { moderate hypoxemia }\end{array}$ & $\begin{array}{l}\text { Significant differences: fewer } \\
\text { treatment failures (patients } \\
\text { requiring noninvasive } \\
\text { ventilation) and fewer } \\
\text { desaturation events with } \\
\text { HFNC } \\
\text { Tolerance and comfort not } \\
\text { objectively compared }\end{array}$ & $\begin{array}{l}\text { Total flows from the air- } \\
\text { entrainment face mask system } \\
\text { not reported } \\
\text { Fisher \& Paykel provided } \\
\text { funding } \\
\text { One author had affiliation with } \\
\text { Fisher \& Paykel }\end{array}$ \\
\hline Sztrymf ${ }^{62}$ & 2011 & $\begin{array}{l}\text { Retrospective observational study } \\
\text { with sequential therapy }\end{array}$ & $\begin{array}{l}38 \mathrm{ICU} \text { patients with hypoxemic } \\
\text { respiratory failure non- } \\
\text { responsive to non-rebreather } \\
\text { reservoir mask } \mathrm{O}_{2} \\
\text { Lung infection predominated } \\
\text { etiologies }\end{array}$ & $\begin{array}{l}\text { Significant difference vs } \\
\text { standard therapy: improved } \\
\mathrm{P}_{\mathrm{aO}_{2}} \text { and } \mathrm{P}_{\mathrm{aO}}{ }_{2} / \mathrm{F}_{\mathrm{IO}_{2}} \text {, reduced } \\
\text { breathing frequency } \\
\text { Identified } 9 / 38 \text { who failed } \\
\mathrm{HFNC} \text { and required } \\
\text { intubation } \\
\text { Significant criteria: sustained } \\
\text { tachypnea post } \mathrm{HFNC}, \\
\text { continued to have } \\
\text { thoracoabdominal } \\
\text { asynchrony }\end{array}$ & $\begin{array}{l}\text { Patients who improved with } \\
\text { HFNC did so rapidly (within } \\
1 \mathrm{~h} \text { ) } \\
\text { Provided impetus to target } \\
\text { HFNC's potential to reduce } \\
\text { frequency of intubation for } \\
\text { hypoxemic respiratory failure } \\
\text { No perceived conflict of interest }\end{array}$ \\
\hline Lenglet $^{63}$ & 2012 & $\begin{array}{l}\text { Prospective observational study } \\
\text { of Optiflow HFNC as } \\
\text { sequential therapy }\end{array}$ & $\begin{array}{l}17 \text { emergency-department patients } \\
\text { with hypoxemic respiratory } \\
\text { failure non-responsive to non- } \\
\text { rebreather reservoir mask } \\
\text { therapy }\end{array}$ & $\begin{array}{l}\text { Significant difference in } \\
\text { Borg scale dyspnea score, } \\
\text { decreased breathing } \\
\text { frequency, increased } \mathrm{S}_{\mathrm{pO}_{2}} \\
\text { Noise from HFNC found } \\
\text { similar to non-rebreather } \\
\text { reservoir mask and ambient } \\
\text { emergency-department noise } \\
\text { level }\end{array}$ & $\begin{array}{l}\text { Small study } \\
\text { Careful patient selection criteria } \\
\text { Emergency-department staff } \\
\text { accepted technical aspects of } \\
\text { HFNC system }\end{array}$ \\
\hline
\end{tabular}


nificant difference in patient tolerance in favor of the HFNC. Although also not statistically significant, there was a positive trend toward patient comfort for the HFNC group. ${ }^{59}$

Also published in 2010 was a prospective sequential comparison trial by Roca et al, using HFNCs with 20 patients identified as having hypoxemic respiratory failure refractory to conventional $\mathrm{O}_{2}$ therapy. ${ }^{60}$ These patients were selected if they did not increase their $\mathrm{S}_{\mathrm{pO}_{2}}>96 \%$ after receiving standard oxygen therapy, which consisted of a combination LFNC and $\mathrm{O}_{2}$ via face mask (estimated $\mathrm{F}_{\mathrm{IO}_{2}}=0.5$ and total flow $15 \mathrm{~L} / \mathrm{min}$ ). After $30 \mathrm{~min}$, ABGs, vital signs, and subjective evaluation of the face mask system's comfort were evaluated. The patients were then switched to HFNC, using a Fisher \& Paykel humidifier and OptiFlow cannula, and the patient response was reassessed. The face mask's estimated $0.5 \mathrm{~F}_{\mathrm{IO}_{2}}$ was maintained by adjusting $\mathrm{HFNC}$ air/ $\mathrm{O}_{2}$ flow meters, but total flow was set at $20 \mathrm{~L} / \mathrm{min}$ and could be increased to $30 \mathrm{~L} / \mathrm{min}$ if needed. Statistical significance was noted in increased oxygen levels and reduction in breathing frequency. $\mathrm{P}_{\mathrm{aO}_{2}}$ with mask increased from a mean value of 77 to $127 \mathrm{~mm} \mathrm{Hg}$ with HFNC. Breathing frequency while mask breathing dropped from a mean of 28 to 21 breaths/min after switching to the HFNC; $\mathrm{P}_{\mathrm{aCO}_{2}}$ and $\mathrm{pH}$ were unchanged. Subjective evaluations for comfort (dyspnea, mouth dryness, and overall comfort) also favored the HFNC. Of interest were that some patients experienced cervical-thoracic discomfort with HFNC, which abated after reducing total flow. 60

In 2011 Parke and coauthors published a prospective randomized comparison study of 60 patients admitted to a cardiothoracic and vascular ICU with mild to moderate hypoxemic respiratory failure. ${ }^{61}$ The patients presented with a wide range of baseline room-air $\mathrm{P}_{\mathrm{aO}}$ levels, which ranged from 56-92 $\mathrm{mm} \mathrm{Hg}$. Dyspnea was identified by tachypnea (breathing frequency $\geq 25$ breaths/min) and/or other clinically observable signs. Study enrollment was based on hypoxemia and dyspnea, which persisted after treatment with either LFNC ( $\geq 4 \mathrm{~L} / \mathrm{min}$ ) or oxygen face mask ( $\geq 6 \mathrm{~L} / \mathrm{min}$ ). Patients were randomly placed on either OptiFlow HFNC or oxygen by air-entrainment diluter with an aerosol-type face mask; similar Fisher \& Paykel heated humidifiers were used for both systems. There was no crossover in therapy. The outcomes evaluated were fewer treatment failures within 24 hours of treatment (patients required more aggressive treatment, consisting of NIV) and improved patient tolerance/comfort. Technical issues to note were that, as patients were placed on the HFNC system, flow level began at $35 \mathrm{~L} / \mathrm{min}$ and was increased to potentially $60 \mathrm{~L} / \mathrm{min} ; \mathrm{F}_{\mathrm{IO}_{2}}$ was also independently titrated to achieve an $\mathrm{S}_{\mathrm{pO}_{2}}$ of $\geq 95 \%$. With the face mask system, total system flows were not reported (either calculated or measured). There was potential for the total flow to decrease as $\mathrm{F}_{\mathrm{IO}_{2}}$ was increased at the air-entrainment diluter. This is especially critical with an open-design face mask, as mask outlet holes allow secondary room entrainment if the patient's inspiratory flow demand is not met. This spiral of dyspnea and hypoxia causing increasing tachypnea can be accelerated as the diluter is adjusted to higher $\mathrm{F}_{\mathrm{IO}_{2}}$, which further decreases the system's total flow. Results of the comparison did identify statistically significantly fewer treatment failures in the HFNC group. Desaturation events were less common in the HFNC group (0.79/patient), compared to those receiving face mask oxygen (1.86/patient). It was not possible to analyze if the reason for this related to improved $\mathrm{O}_{2}$ delivery characteristics, mild distending pressures of the HFNC system, or problems with the mask being removed for communicating, eating/drinking, or taking oral medications. The potential of the HFNC system to develop positive airway pressure was not evaluated as a mechanism for improved oxygenation. The lessons provided by this research may be more valuable than only demonstrating that a certain oxygen delivery system was more capable than another. This study illustrated that the challenges of clinical research when matching a device to a patient problem is based both on hard science, critical thinking, and the art of responding to often subtle clinical clues. In addition, the authors noted that some clinicians altered their usual clinical practice by placing 5 patients on HFNC instead of NIV after perceived treatment failure of the face mask. This study provided insight that the more expensive and technically complex HFNC systems may be selected at an intermediate level between more modest devices (LFNC or entrainment masks) and NIV. The authors noted the limitation and difficulty of being able to perform detailed (real-time) analysis of factors that prompted oxygen desaturation episodes and treatment failure. Clinicians involved in research projects are required to have an understanding of technical specifications and limits of an oxygen delivery apparatus but must also balance patient factors such as changing breathing frequency, inspiratory patterns, dynamics of cardiopulmonary disease states, and ethics of placing patient safety before research. ${ }^{61}$

Sztrymf and coauthors performed a non-randomized prospective evaluation of HFNC applied to patients with acute hypoxemic respiratory failure in an ICU setting. ${ }^{62}$ Thirty-eight patients received OptiFlow HFNC oxygen if they failed to achieve an $\mathrm{S}_{\mathrm{pO}_{2}}$ of $\geq 92 \%$ with conventional oxygen therapy of NRB with $\approx 14 \mathrm{~L} / \mathrm{min}$ oxygen flow. HFNC was applied with an $\mathrm{F}_{\mathrm{IO}_{2}}$ of $0.88 \pm 0.016$ and $49 \pm 9 \mathrm{~L} / \mathrm{min}$ flow; $\mathrm{F}_{\mathrm{IO}_{2}}$ was not measured but estimated with the NRB. The etiology of respiratory failure included a wide range of medical problems, with lung infection (70\%) the most common etiology and community-acquired pneumonia being the largest group (39\%). Objective eval- 

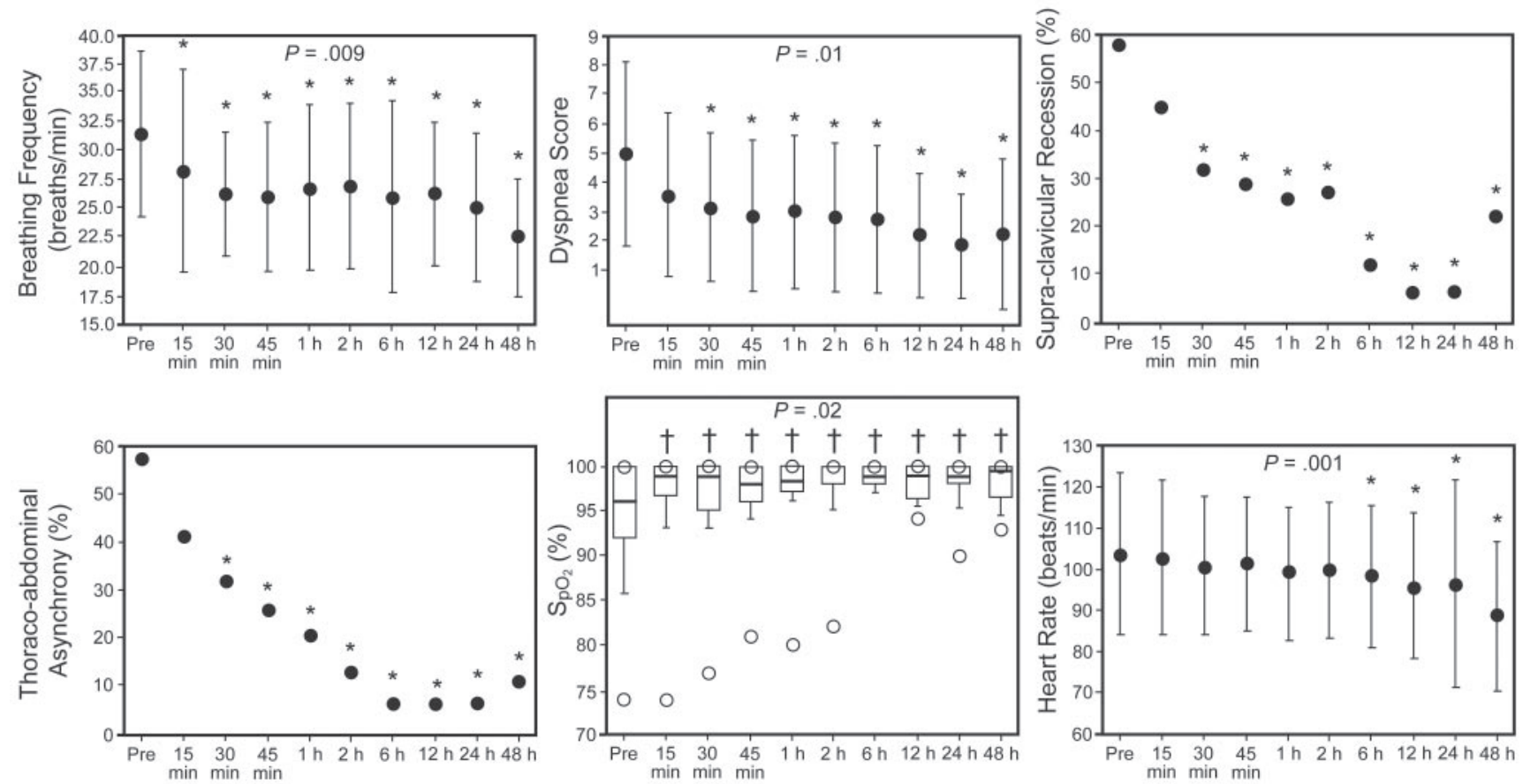

Fig. 11. A: Evolution of clinically observed signs after 38 patients received high-flow nasal cannula oxygen. Mean $\mathrm{F}_{\mathrm{IO}_{2}}$ from OptiFlow cannula was $0.88 \pm 0.16$ with flow of $49 \pm 9 \mathrm{~L} / \mathrm{min}$. Results are expressed as mean $\pm \mathrm{SD}$. The $\mathrm{S}_{\mathrm{pO}_{2}}$ box plots show the medians and interquartile ranges, and the open circles show the maximum values. ${ }^{*} P<.05$ vs before value. $\dagger P<.005$ vs before value. (From Reference 62 , with permission.)

uation after HFNC was initiated included: ABGs and vital signs. Patient tolerance for HFNC was evaluated by a visual numeric scale but not compared to NRB therapy. This study carefully followed patients after they received HFNC. Most notable were observed patterns of breathing frequency and thoraco-abdominal asynchrony. There was fairly rapid improvement in those 2 clinical signs, which also correlated with patients' reported dyspnea score (Fig. 11). Within 1 hour of HFNC therapy, changes in key clinical signs, as well as $\mathrm{P}_{\mathrm{aO}_{2}}$ and $\mathrm{P}_{\mathrm{aO}_{2}} / \mathrm{F}_{\mathrm{IO}_{2}}$ reached statistical significance. In addition, the authors' observations provide insight in using physical exam findings and $A B G$ data to identify and predict treatment failure of HFNC. Nine HFNC patients subsequently required intubation and invasive mechanical ventilation; the majority required intervention within 4 hours. The authors identify the importance of findings of sustained tachypnea and continued thoraco-abdominal asynchrony, as well as blunted oxygenation response post HFNC therapy as significant predictors for HFNC failure. 62

The same group followed their previous ICU-patient evaluation with a similar prospective observational study to evaluate patients with hypoxemic respiratory failure in an emergency department (ED) setting. ${ }^{63}$ After initial assessment to gauge inclusion criteria, the OptiFlow cannula was applied to patients if they remained hypoxemic $\left(\mathrm{S}_{\mathrm{pO}_{2}}\right)$ with clinical signs of dyspnea after receiving standard therapy with NRB with 10-15 L/min oxygen flow. Of 178 patients who initially received oxygen therapy upon ED admission, 17 patients met inclusion criteria for HFNC therapy; respiratory infection was the most common diagnosis. HFNC was applied with $\mathrm{F}_{\mathrm{IO}_{2}}$ between 0.7 and 1.0, with flows of 30-40 L/min. Response to HFNC was monitored at 15, 30, and $60 \mathrm{~min}$ after its initiation. Similar to the aforementioned studies, when compared to patient data collected during NRB therapy, the authors found statistically significant reductions in breathing frequency, and increase in $\mathrm{P}_{\mathrm{aO}}$. Eight out of 9 patients were able to complete Borg and visual analog scale scoring, which identified preference for the HFNC. They concluded that HFNC therapy systems could feasibly be used in the ED setting and could be considered as a first line option for selected patients who represented more severe hypoxemic failure after simpler oxygen devices failed to adequately oxygenate. ${ }^{63}$

The aforementioned observations and controlled studies provide several common findings on clinical application of HFNCs in adult care.

- The HFNC offers potential for improved oxygen delivery for a majority of patients with moderate hypoxemic respiratory failure. 
- The HFNC can be adapted for use in a variety of clinical settings (exercise lab, ED, and ICU).

- The physical exam findings of reduction in breathing frequency can provide a reliable guide to predict improved oxygenation, as well as treatment failures, in addition to $\mathrm{S}_{\mathrm{pO}_{2}}$ monitoring.

To date, evaluations of HFNC therapy have been most frequently conducted as retrospective audits or prospective comparison studies. The most common alternative device was the NRB, with inlet flows of $10-15 \mathrm{~L} / \mathrm{min}$. The oxygen delivery performance of that mask fell short of the HFNC in matching inspiratory flow demand in adults with hypoxemic respiratory failure who had respiratory frequency $>25$ breaths/min. Flow to the NRB may be limited by clinicians who fail to advance flows higher than the traditionally accepted levels or the modest size of the bag's reservoir $(\approx 0.6 \mathrm{~L})$. Although limited, there is some evidence that the HFNC may better match adult patients' high inspiratory flow demand to then interrupt the vicious circle of hypoxemia-dyspneatachypnea. The mechanism is likely some combination of higher bulk flow preventing secondary room air entrainment, and using anatomic airways as a reservoir during end exhalation. There is no direct evidence to evaluate the proposed mechanism of the HFNC rinsing dead space gas from the upper airways to improve ventilation. It can be inferred from one observational study in which $\mathrm{P}_{\mathrm{aCO}_{2}}$ levels remained constant while breathing frequency decreased by $\approx 4$ breaths/min following HFNC. ${ }^{58}$ There is currently no direct evidence to specifically identify impact of the low-level CPAP by adult HFNCs to treat low ventilation-perfusion regions of lung with distending pressure. In 2 studies, a small number of patients were identified as having either congestive heart failure or cardiogenic pulmonary edema. ${ }^{64,65}$ Based on current evidence it would seem prudent to consider mask CPAP the first line therapy for those patient groups if they can be reliably identified by history, physical exam, and/or echocardiography. Although pressurized facial masks have drawbacks, their threshold pressure levels are more predictable and measurable than with the HFNC. The other feature of HFNC that is more difficult to objectively evaluate is patient tolerance and comfort. The NRB is typically not used with a heated humidification system, and in some circumstances no humidifier is used at all. A number of studies quantitated some visual analog scale, feelings of freedom from mask-induced claustrophobia, improved ability to speak, et cetera. However, there were no clear comparisons of how warm, humidified gas impacted tolerance, comfort, or changes in nasal resistance with HFNC therapy.

\section{Observational and Randomized or Quasi-Randomized Trials for Perinatal Patients}

Although receiving initial acceptance since introduction a few years ago, there have been only a few randomized controlled studies to objectively assess efficacy and to guide patient selection. Study of HFNC for premature and term newborns shares a similar history. Although utilization has increased and generated substantial literature, there have been few published randomized controlled trials. Most studies define "high flow" for premature or term infants as $>1$ or $2 \mathrm{~L} / \mathrm{min}$. As noted, outcomes of clinical analysis of adult HFNC therapy primarily focused on its ability to provide supplemental oxygen. Although oxygen supplementation is a goal, the primary focus for perinatal care has been on HFNC's ability to provide "distending pressure to the lungs." Many observational studies have compared it to traditional NCPAP systems, which, by design, seal in the nares. The Cochrane Collaboration published an analysis of literature of NCPAP administration devices in 2008.50 The goals for the clinical application for either HFNC or NCPAP in premature or term newborn care include 3 main clinical rationales: prophylaxis or treatment of RDS soon after delivery as an alternative to intubation and mechanical ventilation; as post-extubation therapy; and as treatment for apnea of prematurity.

A 2009 "state of the art" review analyzed 9 papers on use of HFNC in preterm infants published up until 2008. ${ }^{66}$ That review included 5 prospective and 2 observational studies, of HFNC with premature and term babies. ${ }^{67-71}$ The objective of 4 prospective studies was either to quantify CPAP levels of HFNCs or to note direct comparison to NCPAP in prophylaxis and/or treatment of RDS. ${ }^{68-71}$ In that group, common findings were as follows.

- There was similar effectiveness of HFNC and NCPAP, with a near linear relationship between distending pressure and HFNC flow level. ${ }^{68-70}$

- Difficulty was noted in either predicting distending pressure based on flow or monitoring pressure level with an HFNC. HFNC systems do not typically have built-in pressure alarms. ${ }^{68-71}$

- It was documented that larger babies required higher flows to create comparable distending pressure. ${ }^{71}$

One of the observational studies only compared effectiveness for treatment of apnea of prematurity, and found no difference with NCPAP. ${ }^{71}$ Sreenan's group used a formula (below) to estimate HFNC flow to infants using a constant-flow device and a Salter Labs infant-size standard nasal cannula, which produced a distending pressure of $4.5 \mathrm{~cm} \mathrm{H}_{2} \mathrm{O} .{ }^{70}$ 


\section{High-Flow Oxygen Administration by Nasal Cannula for Adult and Perinatal Patients}

\section{Estimated HFNC flow $=0.92+0.68 \mathrm{w}$}

where $\mathrm{w}=$ weight in $\mathrm{kg}$. Of the 2 retrospective observational studies, one audited care of babies born at $<30$ weeks gestational age who required therapy for RDS within 96 hours of birth. A cohort of 65 babies with HFNC were compared to 36 who received NCPAP. They found increased use of HFNC; potential reasons were due to greater acceptance by staff because of simplicity, reduced nasal trauma from the HFNC's nasal interface, and improved tolerance compared to NCPAP. There was no statistical difference in outcomes such as need for intubation, development of complications such as barotrauma (eg, pneumothorax), increased work of breathing, or incidence of bronchopulmonary dysplasia. ${ }^{72} \mathrm{~A}$ similar study reviewed infants at 25-29 weeks of gestational age who were placed on HFNC as part of an early extubation protocol. Nonstatistical outcome benefits noted were reduced ventilator days, reduced ventilator-associated pneumonia, and improved growth. ${ }^{73}$

The aforementioned 2009 "state of the art" summary ${ }^{66}$ and the 2011 Cochrane Database ${ }^{73}$ review identified and commented on 4 randomized controlled trials on use of HFNC with preterm infants. ${ }^{74-77}$ Each will be briefly discussed and also summarized in Table 6.

Nair and colleagues compared HFNC to NCPAP in 67 infants randomly assigned to either therapy. ${ }^{74}$ The results were published in abstract form, but the authors provided "additional unpublished data" for the Cochrane analysis. Mean flow with the HFNC was 5-6 L/min; mean NCPAP pressure was 5-6 $\mathrm{cm} \mathrm{H}_{2} \mathrm{O}$. The primary measured outcome was treatment failure that resulted in intubation. Results were comparable $(P=.96) ; 4 / 33$ failed with HFNC, and 4/34 failed CPAP. Secondary outcomes comparing complications (nasal trauma, pneumothorax, sepsis), duration for respiratory support, and length of hospital stay showed no difference. ${ }^{74}$

Campbell et al compared 40 premature infants who, following extubation, were randomized to either HFNC (mean flow of $1.8 \mathrm{~L} / \mathrm{min}$ ) or NCPAP (mean pressure of $\left.5-6 \mathrm{~cm} \mathrm{H}_{2} \mathrm{O}\right) .{ }^{75}$ Of note was that gas from the HFNC was humidified but not heated. The primary outcome was incidence of reintubation within 7 days. The NCPAP generator used was a Viasys Infant Flow system, which uses a fluidic switching (flip-flop) circuit to change flow from inspiration to exhalation. Criteria for intubation included severe apnea and/or acute respiratory acidemia with $\mathrm{pH} \leq 7.25$, or need for $\mathrm{F}_{\mathrm{IO}_{2}} \geq 0.6$. Although a small study, there was a statistically significant $(P=.003)$ increased requirement for reintubation in the HFNC group (12/20) versus those on NCPAP (3/20). The relative risk of HFNC was 2.1 , with a $95 \%$ CI of 1.3-3.0. There were no differences in secondary outcomes or complications. ${ }^{75}$
Woodhead and colleagues performed a random crossover study of 30 neonates who were extubated and then placed on either a heated-humidified Vapotherm system or an unheated-unhumidified high-flow system; the nasal cannulas were not varied. ${ }^{76}$ The infants breathed on one system for 24 hours and then were switched to the alternate system. Primary outcome was treatment failure requiring reintubation. Secondary outcome evaluations were changes in appearance of nasal mucosa and physical examination score of increased respiratory effort. The humidified Vapotherm group had no treatment failures. In the unhumidified cannula group, 2/15 required reintubation within 24 hours after evaluation revealed hypercapnia and atelectasis that failed to respond to increasing cannula flow. Five failed in the unhumidified group in the second 24 hours; 2 because of apnea events, 2 from hypercapnia and tachypnea, and 1 due to increasing $\mathrm{F}_{\mathrm{IO}_{2}}$ requirement. All 5 improved after being switched back to heated-humidified Vapotherm therapy. ${ }^{76}$

Miller and Dowd conducted a randomized controlled study comparing 2 different brands of humidifier: Fisher \& Paykel and Vapotherm. Both systems were set to deliver $6 \mathrm{~L} / \mathrm{min}$ to HFNCs supplied by the respective companies. ${ }^{77}$ Thirty-nine infants with an average gestational age of 28.2 weeks were studied; all previously had required intubation for respiratory failure. The primary outcome was rate of extubation failure, defined as reintubation within 72 hours of receiving either HFNC system. Criteria were set based on level of hypercarbia, acidosis, or increased requirement for $\mathrm{F}_{\mathrm{IO}_{2}} \geq 0.7$. Acquisition cost analysis was also noted. All infants were followed for 1 week for secondary effects, including development of chronic lung disease. Results showed no statistical difference in need for reintubation within 72 hours $(P=.69)$ using either brand of humidifier or cannula. There were also no differences in adverse events or other complications between either system. ${ }^{77}$

The Cochrane Collaboration reviews found 4 methodologically sound randomized trials..$^{73}$ However, the small number of premature patients studied limited statistical power, and differing primary outcome comparisons prevented meta-analysis. Some data were not available to evaluate some secondary outcomes for subgroup analysis. The primary outcome for several studies was comparison of HFNC following extubation versus NCPAP. Analysis showed mixed results. One study showed no difference, yet another revealed increased rates of reintubation with HFNC.76,77 However, the studies varied technically in terms of flow rates, gas humidification, and design. Unfortunately, none examined the effect of differing flows or cannula sizes, which affect distending pressures. No differences were found in brand of humidification system. The primary conclusion from the Cochrane group was that there was insufficient evidence 
High-Flow Oxygen Administration by Nasal Cannula for Adult and Perinatal Patients

Table 6. Randomized Controlled Trials of HFNC with Preterm Infants

\begin{tabular}{|c|c|c|c|c|c|}
\hline First Author & Year & $\begin{array}{l}\text { Type of Study and } \\
\text { HFNC Device }\end{array}$ & $\begin{array}{c}\text { Number of Participants } \\
\text { and Setting }\end{array}$ & Outcomes & Comments \\
\hline $\mathrm{Nair}^{74}$ & 2005 & $\begin{array}{l}\text { Prospective randomized } \\
\text { controlled study } \\
\text { Vapotherm HFNC } \\
\text { vs nasal CPAP }\end{array}$ & $\begin{array}{l}28 \text { newborns (mean gestational } \\
\text { age } 32 \text { weeks) started on } \\
\text { nasal CPAP and randomized } \\
\text { to Vapotherm (13) or nasal } \\
\text { CPAP (15) }\end{array}$ & $\begin{array}{l}\text { No significant difference } \\
\text { in treatment failure } \\
\text { (requirement for } \\
\text { intubation), pH } \leq 7.25, \\
\mathrm{P}_{\mathrm{aCO}_{2}}>60 \mathrm{~mm} \mathrm{Hg} \text {, or } \\
\mathrm{F}_{\mathrm{IO}_{2}} \text { need }>0.7\end{array}$ & $\begin{array}{l}\text { No difference in secondary } \\
\text { outcomes of trauma, other } \\
\text { complications, or duration } \\
\text { of respiratory support }\end{array}$ \\
\hline Campbell $^{75}$ & 2006 & $\begin{array}{l}\text { Prospective randomized } \\
\text { controlled study of } \\
\text { Salter infant HFNC } \\
\text { (unheated) vs Viasys } \\
\text { Infant Flow nasal } \\
\text { CPAP }\end{array}$ & $\begin{array}{l}40 \text { preterm infants with birth } \\
\text { weight } \leq 1,250 \mathrm{~g} \text { who had } \\
\text { previously been intubated }\end{array}$ & $\begin{array}{l}\text { Significantly higher rate of } \\
\text { re-intubation with HFNC } \\
(12 / 20) \text { versus nasal } \\
\text { CPAP }(3 / 20) \text { within } 7 \mathrm{~d} \\
(P=.003) \\
\text { Those who remained on } \\
\text { HFNC had higher } \\
\text { oxygen requirement than } \\
\text { those on nasal CPAP } \\
(P=.04)\end{array}$ & $\begin{array}{l}\text { No difference in trauma to } \\
\text { nares } \\
\text { Nasal CPAP } 5-6 \mathrm{~cm} \mathrm{H}_{2} \mathrm{O} \\
\text { Mean HFNC flow } 1.8 \mathrm{~L} / \mathrm{min} \text {, } \\
\text { but distending pressure not } \\
\text { measured }\end{array}$ \\
\hline Woodhead $^{76}$ & 2006 & $\begin{array}{l}\text { Prospective randomized } \\
\text { crossover trial } \\
24 \text { h of either heated } \\
\text { and humidified } \\
\text { Vapotherm HFNC } \\
\text { or standard non- } \\
\text { humidified nasal } \\
\text { cannula }\end{array}$ & $\begin{array}{l}30 \text { neonates with mean } \\
\text { gestational age of } 32 \text { weeks } \\
\text { who had previously been } \\
\text { intubated }\end{array}$ & $\begin{array}{l}\text { No significant difference } \\
\text { in rate of re-intubation } \\
(P=.25) \\
\text { Favored humidified HFNC } \\
\text { Significant difference in } \\
\text { more normal mucosa } \\
\text { in humidified group } \\
(P<.001) \text {, and lower } \\
\text { respiratory effort score } \\
(P=.05)\end{array}$ & $\begin{array}{l}\text { Mean flow was } 3.1 \mathrm{~L} / \mathrm{min} \\
\text { with humidified HFNC } \\
\text { and } 1.8 \mathrm{~L} / \mathrm{min} \text { with } \\
\text { unheated-HFNC } \\
\text { Distending pressures not } \\
\text { measured } \\
5 / 15 \text { failures in second } 24-\mathrm{h} \\
\text { period of non-humidified } \\
\text { responded after switching } \\
\text { back to humidified HFNC }\end{array}$ \\
\hline Miller $^{77}$ & 2010 & $\begin{array}{l}\text { Prospective randomized } \\
\text { controlled trial } \\
\text { Fisher \& Paykel } \\
\text { humidified HFNC } \\
\text { (model not stated) } \\
\text { vs Vapotherm } \\
\text { humidified HFNC } \\
\text { (model not stated) }\end{array}$ & $\begin{array}{l}39 \text { neonates with average } \\
\text { gestational age of } \\
28.2 \text { months who had } \\
\text { previously been intubated }\end{array}$ & $\begin{array}{l}\text { No significant difference } \\
\text { in rate of re-intubation } \\
\text { within } 72 \mathrm{~h}(P=.69) \\
\text { No differences in adverse } \\
\text { effects within } 1 \text { week }\end{array}$ & $\begin{array}{l}\text { Distending pressures not } \\
\text { measured } \\
\text { Acquisition cost less with } \\
\text { Fisher \& Paykel device } \\
\text { Less tubing rainout with } \\
\text { Vapotherm device } \\
\text { Funding provided by } \\
\text { Vapotherm and Fisher \& } \\
\text { Paykel } \\
\text { No apparent conflict of } \\
\text { interest }\end{array}$ \\
\hline Abdel-Hady ${ }^{78}$ & 2011 & $\begin{array}{l}\text { Prospective randomized } \\
\text { controlled trial } \\
\text { Sustained nasal CPAP } \\
\text { vs nasal CPAP until } \\
2 \mathrm{~L} / \mathrm{min} \text { HFNC }\end{array}$ & $\begin{array}{l}60 \text { neonates gestational age } \\
\geq 28 \text { weeks } \\
\text { Stable on nasal CPAP for } 24 \mathrm{~h} \\
30 \text { stayed on nasal } \mathrm{CPAP} \text { of } \\
5 \mathrm{~cm} \mathrm{H}_{2} \mathrm{O} \text { until } \mathrm{F}_{\mathrm{IO}_{2}} 0.21 \\
30 \text { transitioned to } 2 \mathrm{~L} / \mathrm{min} \text { on } \\
\text { nasal cannula at } \mathrm{F}_{\mathrm{IO}_{2}} 0.3\end{array}$ & $\begin{array}{l}\text { Significant differences: } \\
\text { sustained nasal CPAP } \\
\text { had fewer days on } \\
\text { supplemental } \mathrm{O}_{2} \\
(P<.001) \text {, shorter } \\
\text { duration of respiratory } \\
\text { support: } 10.5 \mathrm{~d}[4-21 \mathrm{~d}] \\
\text { vs } 18 \mathrm{~d}[11.5-29 \mathrm{~d}], \\
P=.03 \\
\text { No difference in weaning } \\
\text { off nasal CPAP }\end{array}$ & $\begin{array}{l}\text { 19/30 HFNC infants }(63 \%) \\
\text { did not require } \mathrm{F}_{\mathrm{IO}_{2}} \\
>0.21 \text { but needed } \\
\text { distending pressure of } \\
\text { HFNC before weaning } \\
\text { from HFNC }\end{array}$ \\
\hline
\end{tabular}

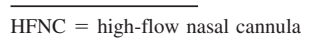

to evaluate safety or efficacy of HFNC in preterm infants. They recommended further randomized studies with adequate power to better compare it to NCPAP. Outcomes should include mortality, incidence of develop- ment of chronic lung disease, and need for and duration of respiratory support. Details on technical strategies need to be better studied. Such information may allow analysis to better identify both overall effectiveness and sub- 
groups who may benefit from HFNC. A prospective randomized controlled study published after the Cochrane reviews examined HFNC in a slightly different application. Abdel-Hady and colleagues evaluated HFNC at $2 \mathrm{~L} / \mathrm{min}$ as a potential weaning or bridge therapy for preterm infants following NCPAP therapy. ${ }^{78}$ Sixty neonates were randomized to either transition from NCPAP to HFNC when their $\mathrm{F}_{\mathrm{IO}_{2}}$ requirement was $\leq 0.3$ or remained on NCPAP until $\mathrm{F}_{\mathrm{IO}_{2}}$ could be decreased to 0.21 . The results showed that infants with NCPAP had statistically fewer days' exposure to supplemental oxygen, and shorter duration of respiratory support than the HFNC group. ${ }^{78}$

\section{Observational and Randomized or Quasi-Randomized Trials of HFNC for Pediatric Patients}

Application of HFNC therapy to children has not received as extensive review, compared to the preterm and neonatal patient populations. One prospective observational study included 46 consecutive patients who ranged in age from newborns to 12 years of age; the median age was 2.8 years. ${ }^{79}$ Patients were assessed after being initially placed on oxygen hood, non-humidified LFNC, or oxygen face mask, and then after being switched to HFNC using Vapotherm technology. HFNC flow levels were set at 8-12 L/min for infants and $20-30 \mathrm{~L} / \mathrm{min}$ for children. Tolerance was evaluated before and after change to HFNC, using a modified COMFORT scale. Analysis of both tolerance and improved arterial oxygen saturation $\left(\mathrm{S}_{\mathrm{aO}_{2}}\right)$ within the first 60-90 min reached the significant level. ${ }^{29}$ A 5-year retrospective analysis was conducted to review 298 infants $<24$ months who received HFNC in a pediatric ICU. The majority required oxygen therapy for viral bronchiolitis. In that patient group, 19\% required escalation from HFNC to noninvasive ventilatory support, and $12 \%$ required intubation and mechanical ventilation. However, over the 5 year period the overall need for intubation dropped from $37 \%$ to $7 \%$ for children with viral bronchiolitis. This trend was not found in children with other pathologies, such as cardiac diseases. ${ }^{80}$

\section{Summary}

The practice of respiratory medicine has benefitted from a growing body of knowledge to support evidence-based practice of medical gas therapy and to guide clinical pathways to blend patient assessment with selection and use of equipment. ${ }^{14-16,23}$ Such themes may contrast with historical, regional/local practice variations, or imposed administrative decisions. Accurate medical information may become clouded by promulgation of often untested information by textbooks. A scientific, comprehensive, and patient-oriented approach to providing supplemental oxygen can be complex. Assessment of need requires evaluation of the patient scenario, medical-surgical history, preexisting medical conditions, treatment setting, and technical limitations of oxygen systems. There is a cognitive process of developing a differential diagnosis of hypoxemia. That process can be further complicated by comorbidities of cardiovascular or neuromuscular disorders; either or both of which may lead to concomitant hypercapnia. There are also realities of equipment availability and increasing pressures for cost constraint. Finally, human issues must be considered in terms of convenience, adherence, and patient comfort. Above all is the regard for patient safety.

Not unlike new or updated adaptations of respiratory care equipment, patient application of HFNCs preceded extensive testing and clinical trials. However, there has been a concerted effort to evaluate the efficacy and to identify clinical roles for the HFNC within the spectrum of oxygen delivery devices. The following appear to be reasonable statements based on published observational and randomized controlled studies in adults. ${ }^{58-63}$

- The HFNC can effectively be used to treat patients with moderate levels of hypoxemic respiratory failure.

- HFNC could be considered as an initial appliance in certain settings (eg, ED), as flow could be titrated based on response over a full range without having to change to other devices. It could also be viewed as an alternative delivery interface for situations in which hypoxemia or dyspnea was not corrected after a trial of low-flow cannula, NRB and/or air-entrainment mask with $\mathrm{F}_{\mathrm{IO}_{2}}>0.4$. Besides $\mathrm{ABGs}$ and $\mathrm{S}_{\mathrm{pO}}$, physical exam findings of sustained tachypnea and thoraco-abdominal synchrony can provide valuable clinical evidence that $\mathrm{O}_{2}$ delivery systems with lower cost and more modest technology have failed. ${ }^{62}$

- HFNC systems offer independent adjustment of $\mathrm{F}_{\mathrm{IO}_{2}}$ and flow. That design feature can allow greater flexibility to match the needs of acutely ill patients. Higher bulk flow can match the inspiratory flow demands of tachypneic patients, which can prevent secondary air entrainment at the facial interface. It is likely that the anatomic airways serve as an oxygen reservoir with the HFNC.

- Low upper airway distending pressures, similar to CPAP, can be achieved with HFNC, yet are difficult to measure and not predictable. ${ }^{45,46}$

- Heated and humidified gas from HFNCs appears to provide improved comfort and allows greater tolerance, compared to oxygen delivered by face masks. This may provide an advantage to patients with marginal oxygenation, for whom removing a face mask for clear speech, eating, drinking, and/or need to frequently ex- 


\section{High-Flow Oxygen Administration by Nasal Cannula for Adult and Perinatal Patients}

pectorate to clear pulmonary secretions, may precipitate hypoxemia.

- Use of HFNC will likely require some additional education for nursing and medical staff. The appearance of a nasal cannula therapy may be perceived as a device that would only be associated with a low severity of illness. In reality, some HFNC patients may be receiving both high $\mathrm{F}_{\mathrm{IO}_{2}}$ and high flow to maintain acceptable oxygen levels.

Although adult HFNCs can provide continuous flow $\geq 40 \mathrm{~L} / \mathrm{min}$, such levels may still not meet high inspiratory flow demands of some profoundly dyspneic patients. Maximum flow capabilities of HFNCs are only about half of those that can be delivered by free-standing continuous high-flow systems, such as high-flow blenders (eg, the Downs Flow Generator or the Caradyne WhisperFlow), using either an open face mask or well-sealing CPAP masks. ${ }^{81}$ Besides better meeting higher inspiratory flow demands, designated adult CPAP systems are typically designed to provide both higher and controllable CPAP pressure. Either high-continuous-flow CPAP systems or demand-flow systems in noninvasive mechanical ventilators are standard therapy for patients with severe atelectasis or heart failure with cardiogenic pulmonary edema. ${ }^{64,65}$ HFNC therapy should also be used with caution in patients with pathophysiologic disorders that are likely to result in intrinsic PEEP, such as unstable COPD or acute asthma. Use of CPAP to counteract intrinsic PEEP is controversial and may result in unintended increase in lung volume in some patients. ${ }^{82,83}$ HFNC therapy is not appropriate for patients with acute hypercapnia for whom NIV or intubation and mechanical ventilation are indicated. The proposed mechanism and level of ability of HFNCs to clear anatomic airway dead space have not been clearly documented. There may also be a small role for HFNC as an alternative to NIV for patients for whom comfort care and do-not-intubate status have been identified. ${ }^{84}$

HFNC for use with premature and neonatal patients has been promoted as a more convenient and "gentler" method to provide NCPAP. At this time, evidence by well-powered and randomized trials is inadequate to determine if HFNC has equivalent efficacy as NCPAP for prophylaxis or treatment of RDS as well as post-extubation therapy following intubation and invasive mechanical ventilation..$^{72}$ There are safety concerns for developing unintended high airway pressure; circuit pressure relief valves should be used and airway pressure monitored. Future clinical research may be better able to focus on longer-term clinically important outcomes, details on cannula size, flows, and measurement of distending pressure.

Randomized controlled trials have become a cornerstone of evidence-based practice. However, in the process of controlling variables such as patient cohorts and precise protocols, findings may lose the ability to be generalizable to clinical realities of the real worlds of the ED, ICU, or neonatal ICU. ${ }^{85}$ As physicians, nurses, and respiratory therapists incorporate the HFNC in their clinical practice, they should be encouraged to conduct research or carefully record their observations as they apply this medical gas interface within the "realities" of their clinical settings and the individual patient's needs.

\section{ACKNOWLEDGMENT}

The author is grateful to James Jamieson RRT and Bryan Wattier RRT, for their assistance with digital figure images for use in this paper and at the Oxygen Journal Conference presentation.

\section{REFERENCES}

1. Leigh JM. The evolution of the oxygen therapy apparatus. Anesthesia 1974;29(4):462-485.

2. Barach AL. Administration of oxygen by nasal catheter. JAMA 1929; 93(16):1550-1551.

3. Kory RC, Bergmann JC, Sweet RD, Smith JR. Comparative evaluation of oxygen therapy techniques. JAMA 1962;179(10):123-128.

4. Barach AL. Principles and practices of inhalational therapy. Philadelphia: JB Lippincott; 1944.

5. Winchell SM. Inhalation of oxygen. In: Safar P, editor. Respiratory therapy. Philadelphia: FA Davis; 1965:154.

6. Shulman M, Schmidt G, Sadove MS. Evaluation of oxygen therapy devices by arterial oxygen tension. Dis Chest 1969;56(4)356-359.

7. Cherniack RM, Hakimpour R. The rational use of oxygen in respiratory insufficiency. JAMA 1967;178(3):178-182.

8. Leigh JM. Variation in performance of oxygen therapy devices. Ann R Coll Surg Engl 1973;52(4):71-73.

9. Gibson RL, Comer PB, Beckham RW, McGraw CP. Actual tracheal oxygen concentrations with commonly used oxygen equipment. Anesthesiology 1976;44(1):71-73.

10. Markovitz GH, Colthurst J, Storer TW, Cooper CB. Effective inspired oxygen concentration measured via transtracheal and oral gas analysis. Respir Care 2010;55(4):453-459.

11. Schacter EN, Littner MR, Luddy P, Beck GJ. Monitoring of oxygen delivery systems in clinical practice. Crit Care Med 1980;8(7):405409.

12. Wettstein RB, Shelledy DC, Peters JI. Delivered oxygen concentrations using low-flow and high-flow nasal cannulas. Respir Care 2005; 50(5):604-609.

13. Bazuaye EA, Stone TN, Corris PA, Gibson GJ. Variability of inspired oxygen concentration with nasal cannulas. Thorax 1992;47(8): 609-611.

14. O'Driscoll BR, Howard LS, Davison AG. BTS guideline for emergency oxygen use in adult patients. Thorax 2008;63(Suppl VI):vi1-vi68.

15. American Association for Respiratory Care. AARC Clinical Practice Guideline. Oxygen therapy for adults in the acute care facility: 2002 revision and update. Respir Care 2002;47(6):717-720.

16. American Association for Respiratory Care. AARC Clinical Practice Guideline: oxygen therapy in the home or alternate site health care facility: 2007 revision and update. Respir Care 2007;52(1):10631068.

17. Terry TL. Extreme prematurity and fibroplastic overgrowth of persistent vascular sheath behind each crystalline lens. Am J Opthalmol 1942;25:203.

18. Rubaltelli DM. Hirose T. Retinopathy of prematurity update. Int Ophthalmol Clin 2008;48(2):225-235. 


\section{High-Flow Oxygen Administration by Nasal Cannula for Adult and Perinatal Patients}

19. Monin P, Vert P. Management of bronchopulmonary dysplasia. Clin Perinatol 1987;14(3):531-549.

20. Walsh M, Engle W, Laptook A, Kazzi SN, Buchter S, Rasmusen M, Quing Y. Oxygen delivery though nasal cannulae to preterm infants: can practice be improved? Pediatrics 2005;116(4):857-861.

21. Vain NE, Prudent LM, Stevens DP, Weeter MM, Maisels J. Regulation of oxygen concentration delivered to infants via nasal cannulas. Am J Dis Child 1989;143(12):1458-1460.

22. Kuluz JW, McLaughlin GE, Gelman B, Cantwell GP, Thomas J, Mahon T, Schleien CL. The fraction of inspired oxygen in infants receiving oxygen via nasal cannula often exceeds safe levels. Respir Care 2001;46(9):897-901.

23. American Association for Respiratory Care. Clinical Practice Guideline. Selection of an oxygen delivery device for neonatal and pediatric patients: 2002 revision and update. Respir Care 2002;47(6):707-716.

24. Shigeoka JW, Bonekat HW. The current status of oxygen-conserving devices (editorial). Respir Care 1985;30(10):833-836.

25. Bar ZG. Predictive equation for peak inspiratory flow. Respir Care 1985;30(9):766-770.

26. Ishikawa S, Nakayama T, Watanabe M, Matsuzawa T. Flow mechanisms in the human olfactory groove: numerical simulation of nasal physiological respiration during inspiration, expiration and sniffing. Arch Otolaryngol Head Neck Surg 2009;135(2):156-162.

27. Kjaergaard T, Cvancarova M, Steinsvåg SK. Relation of nasal air flow to nasal cavity dimensions. Arch Otolaryngol Head Neck Surg 2009;135(6):565-570.

28. Miller MJ, Martin RJ, Carlo WA, Fouke JM, Strohl KP, Fanaroff AA. Oral breathing in newborn infants. J Pediatr 1985;107(3):465-469.

29. Bergeson PS, Shaw JC Are infants really obligatory nasal breathers? Clin Pediatrics 2001;40(10):567-569.

30. Martin RJ, Carlo WA. Role of the upper airway in the pathogenesis of apnea in infants. Respir Care 1986;31(7):615-621.

31. Barach AL, Eduardo R, Pons ER, Berg R. Early use of oxygen in coronary thrombosis. JAMA 1960;174(10):1276-1281.

32. Tiep BL, Nicotra B, Carter R, Belman MJ, Mittman C. Evaluation of low flow oxygen-conserving nasal cannula. Am Rev Respir Dis 1984;130(3):500-502.

33. Tiep BL, Belman M, Mittman C, Phillips R, Ostap B. A new pendant storage oxygen-conserving nasal cannula. Chest 1985;87(3):381-383.

34. Winchell SW. Inhalation of oxygen. In: Safar P, editor. Respiratory therapy. Philadelphia: FA Davis; 1965.

35. Egan DF. Fundamentals of inhalation therapy. St Louis: Mosby; 1969.

36. American Society for Testing Materials. Annual Book of ASTM Standards: F1690-96 standard specifications for medical use. Part 1: general requirements for active humidification systems. Section 13: medical devices and services. West Conshohocken, PA: ASTM; 2001: 1062-1077.

37. Tiep B, Barnett M. High flow nasal vs high flow mask oxygen delivery: tracheal gas concentrations through a heat extension airway model (abstract). Respir Care 2002;47(9):1079.

38. Malinowski T, Lamberti J. Oxygen concentrations via nasal cannula at high flowrates (abstract). Respir Care 2002;47(9):1039.

39. Chatila W, Nugent T, Vance G, Gaughan J, Criner GJ. The effects of high-flow vs low-flow oxygen in advanced obstructive airways disease. Chest 2004;126(4):1108-1115.

40. Waugh JB, Granger WM. An evaluation of 2 new devices for nasal high-flow gas therapy. Respir Care 2004;49(8):902-906.

41. Gregory GA. Kitterman JA, Phibbs RH, Tooley WH, Hamilton WK. Treatment of the idiopathic respiratory-distress syndrome with continuous positive airway pressure. N Engl J Med 1971;284(24):13331340.

42. Locke RG, Wolfson MR, Shaffer TH, Rubenstein SD, Greenspan JS. Inadvertent administration of positive end-distending pressure during nasal cannula flow. Pediatrics 1993;91(1)135-138.
43. Kattwinkel J, Nearmann HS, Fanaroff AA, Katona PG, Klaus MH Apnea of prematurity comparative effects of cutaneous stimulation and nasal CPAP. J Pediatr 1975;86(4):588-592.

44. Martin RJ, Nearman HS, Katona PG, Klaus MH. The effect of a low continuous positive airway pressure on the reflex control of respiration in the preterm infant. J Pediatr 1977;90(6):976-981.

45. Groves N, Tobin A. A High flow nasal oxygen generates positive airway pressure in adult volunteers. Aust Crit Care 2007;20(4):126-131.

46. Parke R, McGuinness S, Eccleston M. Nasal high flow oxygen delivers low level positive airway pressure. Br J Anaesth 2009;103(6): 886-890.

47. Darin JD, Broadwell J, MacDonell R. An evaluation of water vapor output from four brands of unheated prefilled bubble humidifiers. Respir Care 1982;27(1):41-50.

48. ASTM International. F1690-96 standard specification for humidifiers for medical use. West Conshohocken, PA: American Society for Testing Materials; 2004.

49. Centers for Disease Control and Prevention. Ralstonia associated with Vapotherm oxygen deliver device: United States, 2005. MMWR Weekly 2005;54(41)1052-1053

50. De Paoli AG, Davis PG, Faber B, Morley CJ. Devices and pressure sources for administration of nasal continuous positive airway pressure (CPAP) in preterm neonates. Cochrane Database Syst Rev 2008; (4):CD002977.

51. Loftus BC, Ahn J, Haddad J. Neonatal nasal deformities secondary to nasal continuous positive pressure. Laryngoscope 1994;104(8): 1019-1022.

52. Robertson NJ, McCarthy LS, Hamilton PA, Moss ALH. Nasal deformities resulting flow driver continuous positive pressure. Arch Dis Child Neonat 1996;75(3):209-212.

53. Yong SC, Chen CJ, Boo NY. Incidence of nasal trauma associated with nasal prong versus nasal mask during continuous positive airway pressure treatment in very low birthweight infants: a randomized control study. Arch Dis Child Fetal Neonat 2005;90(6):480-483.

54. Frey B, Shann F. Nasopharyngeal oxygen therapy produces positive end-expiratory pressure in infants. Eur J Pediatr 2001;160(9):556-560.

55. Dysart K, Miller TL, Wolfson MR, Shaffer TH. Research in high flow therapy: mechanism of action. Respir Med 2009;103(10):14001405.

56. Kernick J, Margarey J. What is the evidence for the use of high flow nasal cannula oxygen in adult patients admitted to critical care units? A systematic review. Aust Crit Care 2010;23(2):53-70.

57. Calvano TP, Sill JM, Kemp KR, Chung KK. Use of high-flow oxygen delivery system in a critically ill patient with dementia. Respir Care 2008;53(12):1739-1743.

58. Price AM, Plowright C, Makowski A, Misztal B. Using a high-flow respiratory system (Vapotherm) within a high dependency setting. Nurs Crit Care 2008;13(6):298-304

59. Tiruvoipati R, Lewis D, Haji K, Botha J. High-flow nasal oxygen vs high-flow face mask: a random crossover trial in extubated patients. J Crit Care 2010;25(3):463-468.

60. Roca O, Riera J, Torres F, Masclans JR. High-flow oxygen therapy in acute respiratory failure. Respir Care 2010;55(4):408-413.

61. Parke RL, McGuinness SP, Eccleston M. A preliminary randomized controlled trial to assess effectiveness of nasal high-flow oxygen in intensive care patients. Respir Care 2011;56(3):265-270.

62. Sztrymf B, Messika J, Bertrand F, Hurel D, Leon R, Dreyfuss D, Ricard J-D. Beneficial effects of humidified high flow nasal oxygen in critical care patients: a prospective pilot study. Int Care Med 2011;37(11):1780-1786

63. Lenglet H, Sztrymf B, Leroy C, Brun P, Dreyfus D, Ricard J-D. Humidified high flow nasal oxygen during respiratory failure in the emergency department: a feasibility and efficacy study. Respir Care 2012;57(11):1873-1878 


\section{High-Flow Oxygen Administration by Nasal Cannula for Adult and Perinatal Patients}

64. Peter JV, Moran JL, Phillips-Hughes J, Graham P, Bersten AD. Effect of non-invasive positive pressure ventilation (NIPPV) on mortality in patients with acute cardiogenic pulmonary oedema: a metaanalysis. Lancet 2006;367(9517):1155.

65. Vital FM. Saconato H. Ladeira MT. Sen A. Hawkes CA. Soares B. Burns KE. Atallah AN Non-invasive positive pressure ventilation (CPAP or bilevel NPPV) for cardiogenic pulmonary edema. Cochrane Database of Systematic Reviews. (3):CD005351, 2008.

66. Dani C, Pratesi S, Migliori C, Gertini G. High flow nasal cannula therapy as respiratory support in the preterm infant. Pediatr Pulmonol 2009;44(7):629-634.

67. Saslow JG, Aghai ZH, Nakhla TA, Hart JJ, Lawrysh R, Stahl GE, Pyon $\mathrm{KH}$. Work of breathing using high-flow nasal cannula in preterm infants. J Perinatol 2006;26(8):476-480.

68. Kubicka ZJ, Limauro J, Darnall RA. Heated humidified high-flow nasal cannula therapy: yet another way to delivery continuous positive airway pressure? Pediatrics 2008;121(1):82-88.

69. Lampland AL, Plumm B, Meyers PA, Worwa CT, Mammel MC. Observational study of humidified high-flow nasal cannula compared with nasal continuous positive airway pressure. J Pediatr 2009; 154(2):177-182

70. Sreenan C, Lemke RP, Hudson-Mason A, Osiovich H. High-flow nasal cannulae in the management of apnea of prematurity: a comparison with conventional nasal continuous positive airway pressure. Pediatrics 2001;107(5):1081-1083.

71. Shoemaker MT, Pierce MR, Yoder BA DiGeronimo RJ. High flow nasal cannula versus nasal CPAP for neonatal respiratory disease: a retrospective study. J Perinatol 2007;27(2):85-91.

72. Holleman-Duray D, Kaupie D, Weiss MG. Heated humidified highflow nasal cannula: use and a neonatal early extubation protocol. J Perinatol 2007;27(12):776-781

73. Wilkinson D, Andersen C, O’Donnell PFC, DePaoli AG. High flow nasal cannula for respiratory support in preterm infants. Cochrane Database Syst Rev 2011;(5):CD006405.

74. Nair G, Karna P. Comparison of the effects of Vapotherm and nasal CPAP in respiratory distress in preterm infants (abstract). E-PAS 2005;57:2054
75. Campbell DM, Shah PS, Shah V, Kelly EN. Nasal continuous positive airway pressure from high flow cannula versus infant flow for preterm infants. J Perinatol 2006;26(9):546-549.

76. Woodhead DD, Lambert DK, Clark JM, Christensen RD. Comparing two methods for delivering high-flow gas therapy by nasal cannula following endotracheal intubation: a prospective, randomized, masked, crossover trial. J Perinatol 2006;26(8):481-485.

77. Miller SM, Dowd SA. High-flow nasal cannula and extubation success in the premature infant: a comparison of two modalities. J Perinatol 2010;30(12):805-808.

78. Abdel-Hady H, Shouman B, Aly H. Early weaning from CPAP to high flow nasal cannula in preterm infants is associated with prolonged oxygen requirement: a randomized controlled trial. Early Hum Dev 2011;87(3):205-208.

79. Spnentzas T, Minarik M, Patters AB, Vinson B, Sidham G. Children with respiratory distress treated with high-flow nasal cannula. J Int Care Med 2009;24(5):323-328.

80. Schibler A, Pham TMT, Dunster KR, Foster K, Barlow A, Gibbones $\mathrm{K}$, Hough JL. Reduced intubation rates for infants after introduction of high-flow nasal prong oxygen therapy. Int Care Med 2011;37(5): 847-852.

81. Fu C, Caruso P, Janaina J, Lucatto J, Schettino GP, de Souza R, Carvalho CR. Comparison of two flow generators to deliver continuous positive pressure: a test lung study. Int Care Med 2005;31(11): 1587-1591.

82. O'Donoghue FJ, Catcheside PG, Jordan AS, Bersten AD, McEvoy RD. Effect of CPAP on intrinsic PEEP, inspiratory effort and lung volume in severe stable COPD. Thorax 2002;57(6):533-539.

83. Medoff BD. Invasive and noninvasive ventilation in patients with asthma. Respir Care 2008;53(6):740-748.

84. Holets S, Gay P, Peters S. Nasal high flow (NHF) therapy in donot-intubate (DNI) patients with respiratory distress. Respir Care 2012 [Epub ahead of print].

85. Alpert HR, Connolly GN, Biener L. A prospective cohort study challenging the effectiveness of population-based medical intervention for smoking cessation. Tob Control 2012 [Epub ahead of print]. PubMed PMID 22234781

\section{Discussion}

MacIntyre: The Fisher \& Paykel people are pushing hard the notion that high humidity assists secretion clearance. What's your take on that?

Jeff Ward: I've seen that statement in a few articles, yet they never cite published data. I've not yet seen a research abstract promote that premise. Humidity in the nasopharynx and oropharynx doesn't necessarily translate to the lower airways in an opencircuit system like the HFNC. Perhaps in asthmatics there are data that airway dehydration may elicit bronchospasm. ${ }^{1}$ Roca et al found that HFNC was associated with improved patient scoring of mouth dryness and comfort. $^{2}$
I have my students wander about Rochester for a day with a nasal cannula on $2 \mathrm{~L} / \mathrm{min}$. They have to leave campus, go do their laundry, and go shopping with it on, and we make sure they have the tanks with bad wheels. They have to come back the next day and write a report on the experience. I've had several students say they couldn't wear it for more than an hour before their nose stuffed up, and they had no allergic rhinitis or asthma.

The big advantage of humidification, especially at higher flow, is in patient comfort. In most HFNC devices the gas leaves the humidifier like Miami Beach on a summer day. But some systems use a heated wire circuit, which can reduce relative humidity below $100 \%$. The humidity at the nasal prongs is probably less, because preventing condensation can result in decreasing relative humidity and dessication of secretions. ${ }^{3}$ I don't think there are data to show that heated humidified HFNC does anything for secretion retention other than prevent nasal airway drying and increased nasal resistance. Of course, we know that if the nose is unhappy, the lungs can be unhappy too.

Branson: I have a whole bunch of ideas about this. First, all you are doing is adding heat and humidity, and the humidity allows the cannula to change from being a low-flow device to a high-flow device: end of story. Patients have higher oxygen saturation because they get higher $\mathrm{F}_{\mathrm{IO}_{2}}$ : no magic there. But Antonio Esquinas, ${ }^{4}$ from Spain, found that for both high- 
flow $\mathrm{O}_{2}$ and NIV with inadequate humidity it makes it more difficult to intubate the patient. I think the whole HFNC business - the people marketing it initially got it wrong: it improves comfort, and that is enough. They stretch for it improving secretion clearance or outcomes, or preventing intubation, but I think it clearly improves comfort and allows patients to tolerate high-flow oxygen via cannula.

Another concern is that some people say, "Oh, he's on a cannula: he must not be that sick," but he's getting $80 \% \mathrm{O}_{2}$, and I think that-just like we can with NIV-we can leave them on too long before we intervene when they really need to be intubated.

Jeff Ward: I think Dider Dreyfuss ${ }^{5}$ and Jean-Damien Ricard ${ }^{6}$ watched their patients very carefully in the ICU and ED. When they didn't succeed on the standard default system (typically, a non-rebreathing reservoir mask), they put them on HFNC. A substantial number of their patients improved, and those who did not were put on NIV or intubated.

I think it behooves us to watch how patients respond to the devices we use. HFNC is nice because the patient can talk, eat, or drink, whereas with a mask that's not pleasant, especially if they have to be on it for a while. We found that paying attention to both $\mathrm{F}_{\mathrm{IO}_{2}}$ and the patient's flow demand is often valuable after extubation.

At our institution the post-extubation default device was a $40 \%$ all-purpose nebulizer with an aerosol mask. The thinking was - though with no data-that the mist would keep their airways moist, $40 \%$ would prevent hypoxemia, and the total flow of about $50 \mathrm{~L} / \mathrm{min}$ would meet flow demand. However, all that would need to happen was for the patient to get tachypneic from becoming anxious and/or start to desaturate. Then their inspiratory demand pulls in room air and the $\mathrm{F}_{\mathrm{IO}_{2}}$ goes down. The downward spiral would worsen if the $\mathrm{F}_{\mathrm{IO}_{2}}$ of the nebulizer would be turned up to $0.6,0.7$, or 1.0. With high-flow systems like blenders or the HFNC we tend not to see that as much. The flow and $\mathrm{F}_{\mathrm{IO}_{2}}$ can be independently adjusted. Added comfort may make them less anxious and dyspneic.

Branson: We played around with HFNC early on. If you sit a subject so they can't see the device and put them on a nasal cannula with no humidity and say, "Tell me when you can feel it in your nose," it's at 2 or $3 \mathrm{~L} / \mathrm{min}$. Then ask, "When is it uncomfortable?" and it's $7 \mathrm{~L} / \mathrm{min}$. Then ask when they can't stand it for one more second, and it's around $15 \mathrm{~L} / \mathrm{min}$. If you heat and humidify the gas, some people can't feel it until almost $10 \mathrm{~L} / \mathrm{min}$, and it only gets so uncomfortable they can't stand it at 30 or $40 \mathrm{~L} / \mathrm{min}$.

But I agree that all these model studies are unhelpful. HFNC clearly creates CPAP in babies and neonates, and a little in adults. I have seen neonates on 15-18 L/min and you can just see the chest wall expanding, and they're on a substantial amount of CPAP. I have concerns about that. If I came into the Mayo Clinic and said, "Here's my new CPAP system," and you asked, "How do you set the CPAP?" and I said, "Well, you don't," and you asked, "OK, how you do you monitor it?" and I said, "Well, you don't," and you asked, "Where's the safety?" and I said, "It's not important," you might ask me to leave your office.

But HFNC works, and because of its simplicity people have used it, and, perhaps because they couldn't see what they were doing, may have used it inappropriately.

Jeff Ward: I think one of the reasons you had me do this is that I've been around for a long time and seen a lot of snake oil. A lot of the companies do a disservice by making this thing sound like the best thing since sliced bread. Instead of letting the knowledge creep in first and the device/technology come second, the process is reversed. That's not what hap- pens with a new drug, but it's part of life in some aspects of respiratory care, such as new ventilator modes.

I just think it needs to be considered. I don't think HFNCs are the endall, but I think they provide an advantage for-not necessarily a select group, but a relatively middle group of patients, with moderate hypoxemia that can't be relieved by standard and inexpensive devices. But HFNC is a lot more expensive than a cannula and a flow meter. I don't think HFNC should be the default device for every patient in the ED with an $\mathrm{S}_{\mathrm{pO}_{2}}$ of $>90 \%$.

Eiserman:* One thing we've found as a manufacturer is that when people think of a nasal cannula, they say, "What could that hurt?" I think part of the reason for that attitude is the feeling that what's old is new again, and we're looking at the nasal cannula and applications in a different way. It might be really effective in the right patients, but it has led to less interest in researching the possible benefits and effects on outcome, and whether it's equal to or better than other therapies. I think it's because they think of it as just a simple cannula, but more research needs to be done.

Also very important is whether people are considering it $\mathrm{O}_{2}$ therapy or CPAP, because none of these devices are FDA approved or cleared CPAP-generating devices; these are $\mathrm{O}_{2}$ therapy devices. And central to the whole discussion is the critical importance of sizing the cannula. It is meant to be a non-occlusive cannula, and if it completely fills the nares, it's beyond what an HFNC is designed to do. Education is critical and randomized controlled trials are needed, because people think of it as just a cannula. It has a genuine place in the pyramid of care if it's used properly and applied to the right patients, but I

\footnotetext{
* Jeri E Eiserman MBA RRT FAARC, Teleflex, Santa Fe, New Mexico.
} 
look forward to more research and data to see where it fits in the arsenal.

Jeff Ward: I think a lot of people like to paint with a roller or a spray gun: they don't like to use a small brush, which requires thinking as one integrates physical exam findings with other data. With an HFNC one can't measure the CPAP pressure or the delivered oxygen fraction. It's a lot different than using a noninvasive ventilator, with which you have a locked-in $\mathrm{F}_{\mathrm{IO}_{2}}$ and CPAP pressure and you can watch the patient's interaction with the machine, $\mathrm{S}_{\mathrm{pO}_{2}}$, and NIV waveforms. It's more of an art than slapping on a gadget and cranking it up to a number and walking away. We used to do that with IPPB [intermittent positive pressure breathing].

Branson: How many people here use high humidity HFNC in their institutions? [About $75 \%$ of attendees indicate yes.]

Owens: Anecdotally, in our institution the senior residents do all the triage from the floor, and I don't think they appreciate how much support patients are getting on the floor. They say, "Oh, their sats are fine," but they roll into the ICU and need to be intubated almost immediately because their breathing frequency is 50 and they look terrible.
I would agree that more education is needed. I think it's a wonderful device and it's clearly helped people through critical illness, but it goes back to teaching people: don't look at the numbers, look at the patient. Some of the RTs also forget that, and forget how much support that is. The people who really know how much support it is are the anesthesiologists who come up to intubate these patients, and they turn white because they see the patient is on $60 \mathrm{~L} / \mathrm{min}$ and an $\mathrm{F}_{\mathrm{IO}_{2}}$ of 1.0 , because they have to take them off of it and intubate. Great technology, but it's deceptively simple in appearance.

Jeff Ward: A couple blogs ${ }^{7,8}$ have suggested using HFNC instead of face mask to pre-oxygenate prior to and during rapid-sequence intubation.

Kevin Ward: In emergency medicine there's new interest in using HFNC during rapid-sequence intubation, to extend the period of denitrogenation, to reduce the incidence of hypoxemia. ${ }^{9}$

Jeff Ward: It's very difficult to quantify randomized controlled trials on patient comfort. They use visual analog scales, but if you talk to patients who've had this, they say, "This is really cool, I like it." But it's hard to take that to the evidence-based medicine bank.
1. Moloney E, O'Sullivqan S, Hogan T, Poulter LW, Burke CM. Airway dehydration: a therapeutic target in asthma? Chest 2002;121(6):1806-1811.

2. Roca O, Riera J, Torres F, Masclans JR High-flow oxygen therapy in acute respiratory failure. Respir Care 2010;55(4): 408-413.

3. Miyao H, Miyassaka K, Kirokawa T, Hawazoe T. Consideration of the international standard for airway humidification using simulated secretions and an artificial airway. Respir Care 1996;41(1):43-49.

4. Esquinas Rodriguez AM, Scala R, Soroksky A, Bahammam A, de Klerk A, Valipour A, et al. Humidifiers during non-invasive ventilation: key topics and practical implications. Crit Care 2012;16(1):203.

5. Sztrymf B, Messika J, Bertrand F, Hurel D, Leon R, Dreyfuss D, Ricard J-D. Beneficial effects of humidified high flow nasal oxygen in critical care patients: a prospective pilot study. Int Care Med 2011;37(11): 1780-1786.

6. Lenglet H, Sztrymf B, Brun P, Dreyfuss D, Ricard J-D. Humidified high flow nasal oxygen during respiratory failure in the emergency department: a feasibility and efficacy study. Resp Care 2012;(11):18731878.

7. Lin M. Trick of the trade: nasal cannula oxygenation during endotracheal intubation. Acad Life Emerg Med. October 25, 2011. http://academiclifeinem.blogspot.com/ 2011/10/trick-of-trade-nasal-cannula.html. Accessed July 23, 2012.

8. Levitan R. No desat! Nasal oxygen during efforts securing a tube. Emerg Phys Monthly. Posted December 9, 2010. http:// www.epmonthly.com/features/currentfeatures/no-desat. Accessed July 23, 2012.

9. Weingart SD, Levitan RM. Preoxygenation and prevention of desaturation during emergency airway management. Ann Emerg Med 2012;59(3):165-175. 